Florida International University FIU Digital Commons

5-15-1998

\title{
Donde esten mis hijos alli que me entierren. the migration history of Aura Lila Callejas
}

Linda M. Callejas

Florida International University

DOI: $10.25148 /$ etd.FI14052543

Follow this and additional works at: https://digitalcommons.fiu.edu/etd

Part of the Quantitative, Qualitative, Comparative, and Historical Methodologies Commons

\section{Recommended Citation}

Callejas, Linda M., "Donde esten mis hijos alli que me entierren. the migration history of Aura Lila Callejas" (1998). FIU Electronic Theses and Dissertations. 1979.

https://digitalcommons.fiu.edu/etd/1979 


\title{
FLORIDA INTERNATIONAL UNIVERSITY
}

Miami, Florida

\section{“DONDE ESTEN MIS HIJOS ALLI QUE ME ENTIERREN." THE MIGRATION HISTORY OF AURA LILA CALLEJAS}

\author{
A thesis submitted in partial satisfaction of the \\ requirements for the degree of \\ Master of Arts \\ in
}

Comparative Sociology

by

Linda M. Callejas

1998 
To: Arthur W. Herriott, College of Arts and Sciences

This thesis, written by Linda Maria Callejas, and entitled "Donde esten mis hijos, alli que me entierren. The Migration History of Aura Lila Callejas," having been approved in respect to style and intellectual content, is referred to you for judgement.

We have read this thesis and recommend that it be approved.

\author{
Kevin A. Yelvington
}

Betty Hearn Morrow

Kathleen Martin, Major Professor

Date of Defense: May 15, 1998

The thesis of Linda Maria Callejas is approved.

Dean Arthur W. Herriott

College of Arts and Sciences

Dr. Richard L. Campbell

Dean of Graduate Studies

Florida International University, 1998 


\section{DEDICATION}

This work is dedicated

to

my daughter, Mia Lynne

and

to

my grandmother, Juana,

whose influence in my life has been enormous

despite her absence. 


\section{ACKNOWLEDGMENTS}

I would like to thank a number of individuals who made completion of this work possible.

First and foremost, I would like to thank the members of my committee who provided me with direction and vision. My heartfelt gratitude goes to Dr. Kathleen Martin for her continued belief in me. The support which she provided me helped sustain my work on this project for five years. Thanks for keeping the faith. I would like to especially thank Dr. Kevin Yelvington for maintaining a long-distance commitment to this project despite numerous difficulties. Thanks for your patience and understanding. I would also like to especially thank Dr. Betty Hearn Morrow who provided me with insightful comments and advice. Thanks for all your help and support.

I also owe a great deal of thanks to a number of individuals who read my work as it evolved.

I am extremely grateful to Dr. James Ito-Adler for taking an interest in my work and supplying me with numerous references and ideas. His critiques always helped to strengthen my work.

iMuchisimas gracias!

Special thanks also go to Michelle Hsu, Elise Mills, Elena Bee and Jane Morgan, all of whom read this manuscript and helped with the enormous task of editing this work. I am particularly grateful to them for their continued moral support and friendship throughout my work on this project.

Finally, I would like to thank the members of my family who graciously allowed me to present their lives here. I can never fully express my gratitude to my great-aunt, Aura Lila for allowing me to examine her life so closely. She exhibited an enormous amount of patience throughout this process and was always willing to answer more questions despite continued illness. I will always be deeply indebted to her, not only for allowing me to record her words and memories but for all she has done for me throughout my life. I will always admire and respect her greatly. Gracias, Titi.

I would also like to thank my cousin and godmother, Maria, who also allowed me to record her words for this project. She, like her mother, has always served as an example of all that a strong, independent woman can accomplish. Thank you, Madrinita.

Last but not least, I would like to thank my parents. Without their continued love, support and belief in me, I would not have come so far. I will always be deeply indebted to you both. 


\title{
ABSTRACT OF THE THESIS \\ “ADONDE ESTEN MIS HIJOS, ALLI QUE ME ENTIERREN.” THE MIGRATION HISTORY OF AURA LILA CALLEJAS
}

by

\author{
Linda Maria Callejas
}

Florida International University, 1993

\author{
Miami, Florida \\ Professor Kathleen (Logan) Martin, Major Professor
}

\begin{abstract}
"Adonde esten mis hijos alli que me entierren," presents the migration history of my great-aunt Aura Lila Callejas. This work utilizes the oral history method to examine one woman's migration experience in an attempt to identify various theoretical issues. Aura Lila's immigration experience sheds light on a number of different issues, including the reasons why people migrate and how they adapt to an entirely new and often frightening set of circumstances in the country of arrival. The oral history method has proven useful in presenting some of the ways in which structural factors combine with personal motivations to provide the impetus for Aura Lila's journey of international migration. My work with Aura Lila has also served to highlight some of the existing gaps in the current literature regarding Nicaraguans in the United States and the importance of the family within the overall process of migration. Finally, this work explores the nature of the relationship between the researcher and subject within the ethnographic process. While much of Aura Lila's story remains unique and specific to her family's history, her narrative can be related to the growing body of literature focusing on women's life histories.
\end{abstract}


CHAPTER

PAGE

I. INTRODUCTION
A. LITERATURE REVIEW
B. RESEARCH METHODOLOGY
C. WHO IS AURA LILA CALLEJAS?

II. THE CONTEXT OF MIGRATION 13

A. THEORIES OF MIGRATION 13

B. UNITED STATES INVOLVEMENT IN NICARAGUA 15

C. THE NICARAGUAN ECONOMY: 1950-1963

D. “EL PERRO QUE NO SALE A LA CALLE NO ENCUENTRA HUESO"

III. "YO TE CUENTO TODO ESTO PARA QUE VEAS COMO ES LA VIDA, MAMA.” 37

THE IMPORTANCE OF GENDER IN AURA LILA'S LIFE 37

IV. MY ROLE WITHIN THIS PROJECT

A. RESEARCH MOTIVATIONS/METHODOLOGY

B. MY RELATIONSHIP WITH AURA LILA 84 84 87

V. SUMMARY OF FINDINGS 101 LIST OF REFERENCES 106 


\section{LIST OF FIGURES}

FIGURE

PAGE

1. KINSHIP CHART OF CASCO FAMILY 10

2. KINSHIP CHART OF FAMILY OF AURA LILA AND JUAN CALLEJAS _ 11

3. KINSHIP CHART OF FAMILIES OF CASCO SISTERS 93

4. KINSHIP CHART OF CALLEJAS FAMILY 94

5. KINSHIP CHART OF FAMILY OF TERESA AND JIMMY CALLEJAS 95

6. AURA LILA AT AGE 15 96

7. JUANA AT AGE 15

8. JUAN AND AURA LILA IN 1951 96

9. JUAN AND AURA LILA AT A PARTY 97

10. AURA LILA, AGE 29 97

11. MY MOTHER AND AURA LILA AT A PARTY 98

12. AURA LILA'S CHILDREN 98

13. AURA LILA AND JUAN AT THEIR 25TH ANNIVERSARY CELEBRATION

14. AURA LILA ON HER WAY TO WORK 98 99 99 
Chapter I: Introduction

Why did I decide to come? Well, because in Nicaragua my father used to tell me that I should go to the United States because of my children. Because maybe they would have a better education here, than in Nicaragua... I'll never forget the phrase he used, "The dog that doesn't venture out into the street will never find a bone."

_Aura Lila Callejas, Miami, March 1993

In April 1963, my great-aunt Aura Lila Casco de Callejas left Managua, Nicaragua. She flew to the United States with her three children and a niece in hand, in hopes of finding a better life. Yet, when she was reunited with her husband who had migrated a year earlier, she realized that her dreams of prosperity in the United States would cost more than she had ever imagined. Like many women who have migrated to the United States at different historical periods, Aura Lila and her husband decided-with considerable influence from Aura Lila's father-to leave a relatively comfortable lifestyle in their home country for the promise of a better life in the United States. This work will examine Aura Lila's journey—in her own words-in an attempt to provide an individual woman's perspective on migration.

Aura Lila's immigration experience can shed light on a number of different issues, including the reasons why people migrate and how they adapt to an entirely new and often frightening set of circumstances in the country of arrival. Although the results of this research can not be generalized to all Nicaraguan women, Aura Lila's life history presents itself as an opportunity to closely examine how an individual woman's life fits with existing theories of migration. Immigration studies often focus on macro-level theories to explain the reasons people migrate. However, these theories often fail to fully consider the role of the individual within the migration process.

U.S. immigration studies have historically focused on the experiences of men to provide an illustration of the universal immigrant experience, even though more women than men have migrated to the United States since the 1930s (Gabaccia 1992; Simon and Brettell 1986). Research focusing solely on women's immigrations experiences has been criticized for using 
gender as a unit of analysis, which might skew such research to focus on individual motivations (Morokavasic 1983; Leeds 1976: 69). However, other researchers have argued that focusing on women provides much needed balance to studies which have heretofore focused solely on men, and that such research can successfully integrate micro-level and macro-level perspectives (Simon and Brettell 1986). Current research explores more closely various aspects of female migration, including determinants of migration, migration selectivity and the consequences of female migration (Huang 1997). Lim (1990) has identified a relationship between the status of women in the home country and the likelihood that a woman will migrate. According to Huang, Lim argues that the "migration patterns of married women-whether they follow their husbands or remain in the host country"-reflects how well the cultural values of the host country allow for the separation of the husband and wife (Huang 1997: 19). Research has also found that the likelihood that a woman will migrate decreases for married women in "societies where the importance of domestic and reproductive roles" are emphasized (Huang 1997; Fawcett, Khoo and Smith 1984). Huang notes that much of the literature which focuses on immigrant women's adaptation experiences focuses on their labor force participation (1997: 28; Grasmuck and Pessar 1991; Perez, 1984). Oral histories of immigrant women focus more closely on individual motivations and experiences (Gabaccia 1992; Kikumura 1983).

\section{A. Literature Review}

The most significant step I have made in pursuing this research has been the conscious inclusion of feminist theory as a methodological basis for examining the life history of Aura Lila Callejas. When I began work on this project five years ago as an undergraduate,' I gave more weight to Aura Lila's ethnicity than to her gender and to the role it has played throughout her life. This theoretical imbalance is not as uncommon as one might think. Scholars in ethnic and immigration studies often assumed that men and women identified equally within their ethnic cultures, finding a positive refuge in their particular group's "oppositional character," in relation to the larger host society (Gabaccia 1992: xiv). Indeed Corinne Krause has recognized that for many immigrants - men and women alike - and their children, "the ethnic group acted as a 
buffer against a strange and hostile society" (1991: xiii).

When I began this project, I held the ethnic studies position because I was hesitant in identifying the family and the immigrant community as primary arenas of women's oppression. Donna Gabaccia observes that in the past "women's studies scholars increasingly defined the family as the locus of female oppression, not the starting place for cross-gender solidarity" (Gabaccia 1992: xiv). While I understood that women are oppressed and discriminated against within their own households and local communities, I did not feel that my great-aunt had a vision of herself as an oppressed victim nor did she consider her role within the family negatively. Rather for Aura Lila Callejas, as for the three generations of immigrant women studied by Krause in Grandmothers, Mothers and Daughters, "the most significant social context [is] the family" (1991: xii). Aura Lila, as will become clear in her narrative, views herself as a strong woman who has played an elemental role in providing for and helping to support her family in a foreign country. Moreover if we are to use her testimony as a valid indicator of her self-perception, Aura Lila presents herself as someone who has always had to assume a powerful role within her family-before and after her marriage at age 22 .

Within her narrative, it becomes clear that Aura Lila's strength during times of hardship is intimately related to the various roles to which she is associated by virtue of her gender. Prior to her marriage to Juan Callejas, Aura Lila had to assume the role of caretaker within her immediate nuclear family. In addition, she found herself having to help raise her sister's children. According to her testimony, Aura Lila assumed this position without giving much thought to her own personal needs and desires. In a sense, her undertaking of the caretaker role was expected of her, although no one ever explicitly communicated this to her. This particular example serves to illustrate the importance of gender as a powerful influence in women's lives. Such examples are often readily found within women's personal narratives. According to the Personal Narratives Group,

...the dynamics of gender emerge more clearly in the personal narratives of women than in those of men. Certainly men are affected by the social construction of gender, but for men gender has been an unmarked category. For a woman, however, the story is rarely told without reference to the dynamics of gender (1989: 4-5). 
In Aura Lila's case, the importance of gender in the shaping of her life experiences has often been unspoken, assumed or simply, understood.

Feminist researchers interested in recording and analyzing these gender dynamics have increasingly turned to oral history as a methodological tool (Gluck and Patai 1991). Oral history has lent itself particularly well to the collection of women's histories because of its ability to capture the everyday experiences within the "private" realms of home and family life, which have often been ignored in past documentation of historical "facts." For many feminist researchers, the use of oral history has become a conscious means of reinterpreting the established means of acquiring social science knowledge. To this end, Julia Swindells insists that the collection of oral histories be viewed as a powerful tool in critiquing theoretical frameworks that espouse the prime importance of securing objective data. In viewing the oral history method as such, it becomes important not to allow the method to become identified as the domain of women, thereby allowing for the "further diminution of women's history" (Personal Narratives Group 1991: 28). Although critics have challenged the notion that feminist theory can really alter or reconstruct social science paradigms (Strathern 1987), my interest here remains in illuminating areas of social history, specifically women's "private" lives through the use of oral history.

Oral history has a long and distinguished history in anthropology, including the works of Ruth Landes (1969) and Nancy Lurie (1926), which focus on the lives of Native American women. A resurgence of works in the field have embraced the oral history method and documented the effects and pitfalls of using reflexivity in the ethnographic process as a conscious analytical tool (Behar 1996, 1993; Fox 1991).

Although anthropology has often led the social sciences in documenting the relationship between the observer/researcher and the observed/subject (Powdermaker 1966), there is still some debate as to the degree of detachment expected from the ethnographer (Tedlock 1991, Williams 1993). The distance between the outsider/anthropologist and the insider/subject has usually been expressed through the use of binary categories, such as the insider/outsider or the observer/observed divisions, all extensions of the Self/Other dichotomy (Williams, 1993:582585). Recent works consciously attempt to blur the division between these categories by recognizing the presence of the ethnographer within the environment of study (Behar 1993) and 
acknowledging the multiplicity of roles the anthropologist may play within the field: both observer and observed, empathetic outsider, guest and friend/confidante.

Increasingly, the ethnographer can be considered an insider in relation to the social group under study. This is due to the increased diversity of scholars entering the field of anthropology and conducting ethnographic research (Behar 1996: 28; Tedlock 1991: 80). More minorities and women have begun to conduct research on the social groups to which they belong, causing them to carefully examine their position in relation to the subject. Lila Abu-Lughod contends, in Writing Against Culture, that feminist and "halfie" scholars- "people whose national or cultural identity is mixed by virtue of migration, overseas education, or parentage"-most clearly face the question of how to situate themselves in relation to their subjects of study $(1991: 137)$. For Abu-Lughod, feminist and "halfie" anthropologists "cannot easily avoid the issue of positionality within their research" (1991:140).

The emergence of "native" anthropologists has also forced the discipline to more closely examine "the politics of authorship," as Ruth Behar noted in Women Writing Culture (Behar and Gordon 1995: 7). While this emergence has forced the discipline to squarely face the question of cultural representation-"Who are we writing about and for whom?"-native anthropologists must face a number of questions as well. The primary question facing native researchers and "halfies", myself included, concerns our ever-present awareness of the politics of representing Others. As in the case of "halfies" Abu-Lughod contends,

\footnotetext{
As anthropologists, they write for other anthropologists, mostly Western. Identified also with communities outside the West, or subcultures within it, they are called to account by educated members of those communities. More importantly, not just because they position themselves with reference to two communities but because when they represent the Other as they are presenting themselves, they speak with a complex awareness of and investment in reception (1991:142).
}

In Notes of a Native Anthropologist, José Límon discusses the experience of being an anthropologist "born and bred of the place I study...[which] has produced an interesting complexity that the less observant might mistake for a dilemma" (1991: 116). As a result of this "inter- 
esting complexity," the nature of inquiry in the work of many native anthropologists is necessarily informed by the researcher's personal experiences. Native anthropologists who examine the social groups to which they intimately belong echo Renato Rosaldo's assertion, "For me as a Chicano, questions of culture emerge not only from my discipline, but also from a more personal politics of identity and community" (1989: xi).

Consequently, "halfies" and native anthropologists are implicitly questioning another historically essential element in ethnographic research methodology. By redefining the nature of the relationship between the researcher and the subject, they are moving away from characterizing anthropological work as a means of capturing the essence of an exotic and foreign culture, thereby marking the everyday world of the researcher as a valid environment for study (Williams 1993: 582-583). As a result, some anthropologists have begun to examine the most intimate of social groups: their own family. Although critics may reject such research on the basis of seeming too introspective and/or subjective for the collection of valid data, such work has been accomplished successfully (Osborne 1996; Kikumura 1989; Shopes 1984). In Through Harsh Winters: The Life of a Japanese Immigrant Woman (1989), Akemi Kikumura presents the life history of her mother, Michiko Tanaka, an Issei woman, or first-generation Japanese immigrant to the United States. Kikumura was able to use her relationship with her mother as a means of gaining access to her mother's memories of her difficult life in the United States. While Michiko Tanaka's experience is unique, it serves as an illustrative example of the many difficulties that many Issei women faced after leaving Japan, and often, a more comfortable life. Kikumura's generational distance from her mother allowed her to examine the nature of her family's discourse with Japan. Her mother, an Issei with still vivid memories of growing up in Japan, carried on a different relationship with her home country, than did Kikumura, a Nisei or secondgeneration immigrant and the youngest child of seven, born when her mother was in her forties.

\section{B. Research Methodology}

The data used in this project were collected during various interviews conducted from 1993 to 1997. All of the interviews were conducted in Spanish, at Aura Lila's request. I have 
translated all of the interview narrative myself, and I have attempted to relay as closely as possible any idioms to make reading easier. However, I have chosen to preserve some words in Spanish, which preserve the original flavor of the conversation and elude literal translation. I have chosen to remove most of the pauses and utterances, which seem inevitable in the recording of human conversations, in the interest of clarity. I have, however, noted significant pauses in areas of the narrative when I felt that Aura Lila's silences told as much as her story. Otherwise, pauses within the narrative have been noted through the use of ellipses or [....]. Any parenthetical remarks made by the narrator will be found within parentheses, $($ ); while, clarifications that I have added to the text are enclosed within brackets, [ ]. In an effort to provide a clear and concise reproduction of the narrative I have, in some areas, juxtaposed two separate ideas dealing with the same question.

C. Who is Aura Lila Callejas?

Aura Lila Casco de Callejas was born in Masatepe, Nicaragua on April 25, 1930. She was the fifth child of seven born to Inocencio Casco and his wife, Juana Elizabeth. The family lived in Masatepe until Aura Lila was seven years old. The family then moved to Costa Rica, briefly, and returned to Nicaragua nearly three years later, settling in the capital city, Managua. Aura Lila describes her early family life as idyllic, centering on what she describes as a "beautiful relationship" between her parents. Her mother, Juana Elizabeth, had been married to another man prior to her relationship with Inocencio Casco and had borne three children, who were accepted as siblings to the seven Casco children. This practice is in keeping with the general dictates for familial relationships in Nicaragua, where the mother's children are all considered blood kin, despite having different fathers (Randall 1994).

According to Aura Lila, her father Incocencio distinguished himself as a soldier, who fought on the Conservative side, during the civil wars that lasted from 1926 to 1933 and later settled on land which he bought with the salary he received as a member of the National Guard. She says that he was a successful farmer, who was able to feed his family and sell the rest of his harvests for profit. Eventually, he was able to hire various farmhands and build a nice house in 
Managua for his rather large family to live comfortably. With profits from his farm, Inocencio built a beauty salon adjoining his house, so that his wife and daughters could work. In this salon the Casco sisters learned to cut and style hair and were able to work for wages, while remaining within the house.

Aura Lila married Juan Jose Callejas on March 19, 1953. By the time she married, Aura Lila's mother had died of a heart attack and she had taken responsibility for care of her parents' house and the various family members who lived there. These included Inocencio, Aura Lila's two younger brothers, two nieces and a nephew. Aura Lila and Juan had three children of their own-Juan Francisco, born in January 1954; Maria Auxiliadora, born in January 1956; and Ingemar Jose, born in September 1962.

The Callejas family decided to migrate to the United States in 1961, presumably in an effort to find greater material wealth. Juan left first in early 1962 and Aura Lila remained pregnant with her youngest child. She and the children, including her niece-my motherjoined Juan in New York City in April 1963. The Callejas family was able to take advantage of the family reunification policies of the Immigration and Nationality Act of $1952^{2}$ in securing a visa because one of Aura Lila's older sisters and several of Juan's siblings lived in the New York City area. They settled briefly with Aura Lila's sister, Teresa Cuadra and her husband.

After a few years, the Callejas family was able to afford the down payment for a mortgage on a house in the Corona neighborhood of Queens Borough. This working class neighborhood was populated by families of various ethnic backgrounds, including Asian Indian, Cuban, Dominican, Puerto Rican, Chinese, African American and white American. The family lived in Corona until 1981, when they decided to move to Miami, Florida. By then, most of the couple's extended family members - nieces, cousins, brothers and sisters—had moved to Miami where a growing population of Nicaraguans had settled following the Sandinista Revolution of 1979. Aura Lila says they decided to move to Miami in order to remain close to their family members and because she and Juan were tired of New York's winters.

As with their migration from Nicaragua, Juan left first in late 1980, in order to secure employment and a place to live. Aura Lila followed in 1981 with her youngest son, Ingemar, then 16 years old and a nephew, Orlando Cuadra, fifteen. Her oldest children, Juan and Maria, 
remained in New York. Juan Jose decided to remain in New York with his fiancee, whom he eventually married. They now live in Long Island. Maria decided to remain in New York until 1984. She was pregnant at the time that her parents decided to leave New York and didn't want to lose the insurance benefits she received through her job as a medical assistant. Maria says she decided to move to Miami because she needed the support her family would provide in raising her three-year-old son.

In Miami, Aura Lila found a variety of jobs, primarily as a house cleaner and baby sitter. Her work experience in New York had been concentrated in the manufacturing industry, which she did not want to continue once in Miami. According to Aura Lila, she felt too old at age 51 to continue the demanding work of the factory. Within five years, Aura Lila found permanent work with an upper middle-class Cuban family who employed her as a housekeeper and nanny for their two children. She worked with the family until 1988, when she fell ill with kidney failure.

From 1988 to 1991, Aura Lila endured thrice-weekly dialysis and numerous hospital stays, including various episodes where she nearly died. Her daughter, Maria, who had been living with the family since she moved to Miami in 1984, quit work as a nurse in order to attend to her mother full time. In early 1991, Aura Lila received a kidney transplant which quite literally saved her life. Following the transplant, she was able to resume many of her previous activities, including gardening, caring for the family's brood of nine dogs and the general upkeep of the house.

Currently, Aura Lila and Juan live with Maria and Marco, Maria’s 17-year-old son in a middle-class neighborhood in South Miami. Recently, Aura Lila's health lapsed— in late February of this year, she was rushed to the hospital suffering from chest pains. Her hospital stay revealed an enlarged heart and gall stones, which could not be passed due to the fragility of her transplanted kidneys. Doctors have made the decision to remove her gall bladder entirely, and she is now awaiting surgery. Despite the various threats to her health, Aura Lila has remained a strong and vigorous woman in her senior years. 

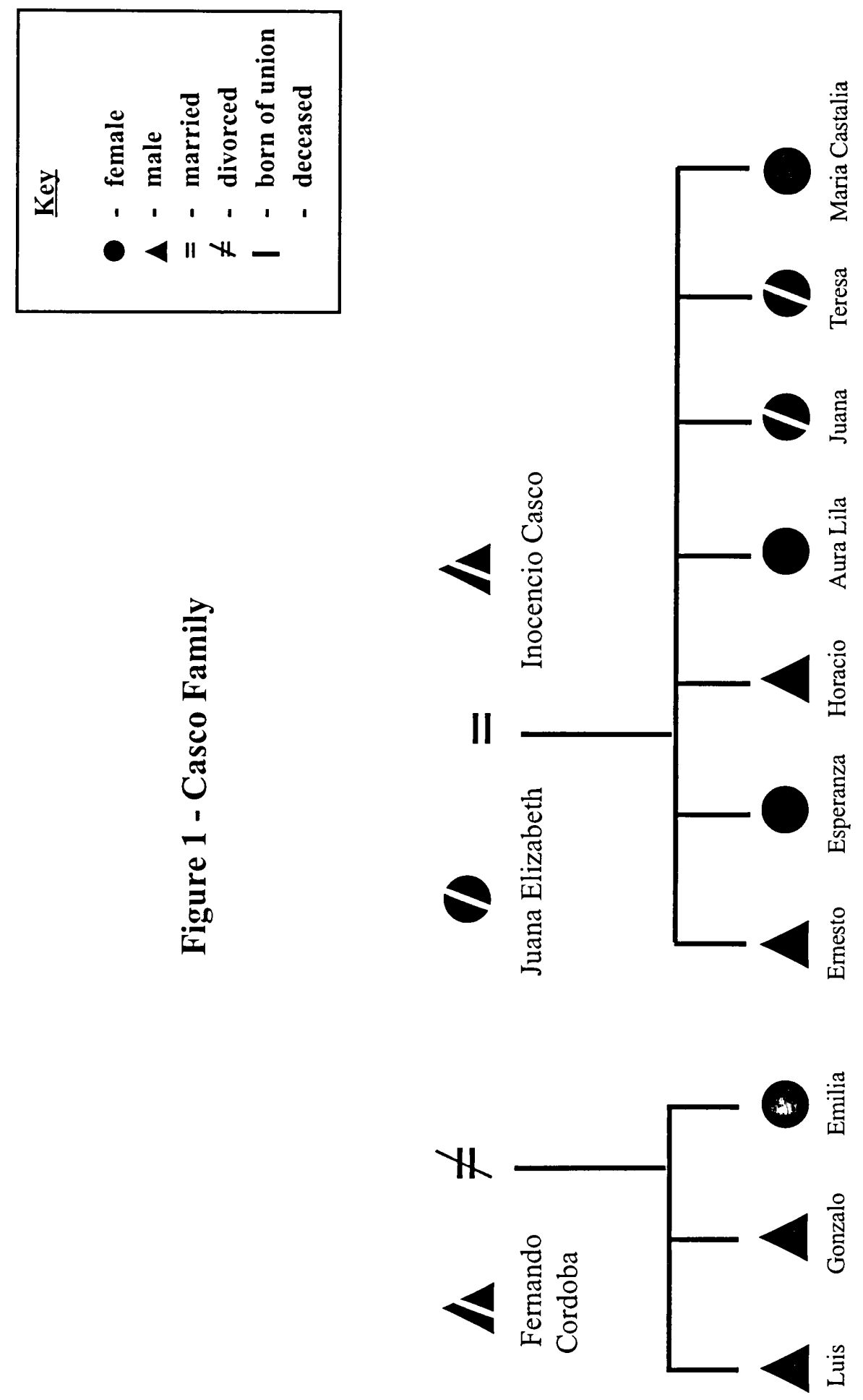


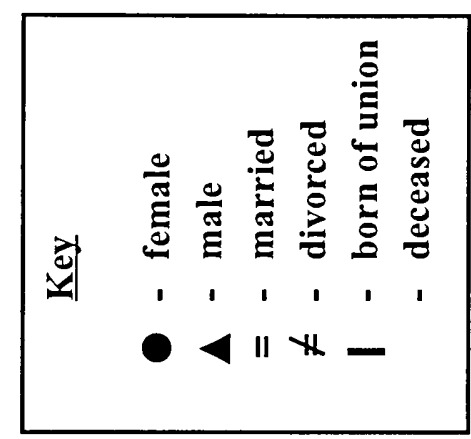

告

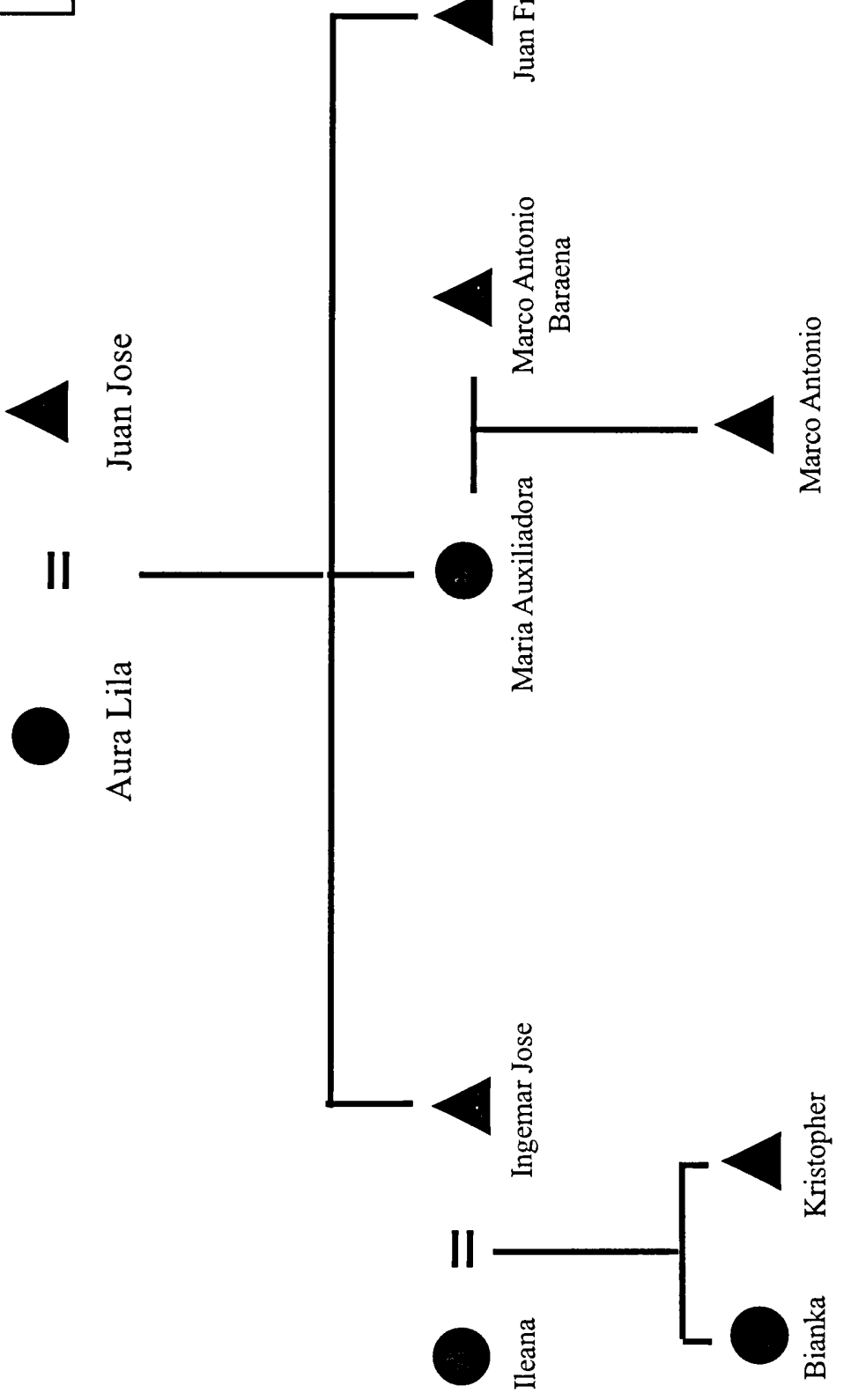


'I chose this topic as part of an undergraduate project in my Qualitative Research Methods course taught at Florida International University by Kathleen Logan in 1993.

${ }^{2}$ The Immigration and Nationality Act of 1952 made changes to existing immigration laws. According to Huang (1997:43), the act created a system in which skills and family connections became the main priorites in determining distribution of visas. 


\section{A. Theories of migration}

Immigration studies often focus on macro-level theories to explain the reasons people migrate. These theories often center the explanation of transnational migration on the economic relations between sending and receiving countries. However, such theories often fail to fully consider the role of the individual within the migration process. In an effort to place Aura Lila's migration experience within the literature, I would like to outline the main theories of international migration.

Classical and neo-classical theories of migration, based on classical theories of economics, postulate that migration occurs as a result of a push-pull phenomenon in which receiving countries provide increased wage/employment opportunities for migrants who come from reduced-opportunity, low-paying countries (Huang 1997; Grasmuck and Pessar 1991). Such theories further speculate that labor and capital flows between sending and receiving nations occurs as a result of international trade relationships which work to maximize the resources each country provides the other (Lim 1989; Martin 1991). At the individual level, push-pull theories argue that individuals make rational choices regarding existing wage differentials between the home and receiving countries. Some of these theories focus on the household or family as the unit of analysis in the effort to maximize overall family income and/or class status or position (Stark and Taylor 1991). Although the individual and/or family is seen as making rational decisions regarding migration, push-pull theories do not fully address the individual role or experience within international migration.

Structural theories of migration expand the push-pull theories by arguing that international trade is ordered by an international division of labor (Huang 1997: 14; Grasmuck and Pessar 1991:5). Based largely on Wallerstein's world systems theory (1974), migration is seen to occur as a consequence of the world market structure that was developed and has expanded since the sixteenth century. Within this scenario, periphery or less-developed countries exhibit a surplus of labor, while core societies exhibit a demand for cheap labor (Grasmuck and Pessar 1991). The chief difference between structural theories of migration and push-pull theories lies in 
the articulation of the relationship between countries, ultimately resulting in international migration. Under this theoretical framework, migration is directly related to core capital investment in the periphery, which often results in a growing demand for cheap labor in the core (Portes 1987). Structural theories of migration focus almost exclusively on a macro-level explanation for migration which greatly obscures the role of individual actors within the migration process.

As noted in the brief discussion on push-pull theories, family networks are important to migration theory. Their importance is further developed in migration network systems theories, which allow for an understanding of the interplay between macro-level and micro-level explanations of international migration (Boyd, 1989; Chávez 1988; Massey et al. 1987; Browning and Rodríguez 1985; Bustamante and Martínez 1979). According to Portes and Rumbaut (1990: 233), international labor migration is best understood as a "socially embedded phenomenon. Networks developed by the movement of people back and forth in space are at the core of the microstructures that sustain migration over time." Such theories highlight the importance of the family as a unit of analysis, while taking into consideration the structural factors which influence family decisions, through "conceptualization and value formation" (Huang 1997: 17; Boyd 1989:286). Within this framework, migration occurs through the function of networks created by families over space and time. Families with a history of migration are seen as providing an established pattern of migration which enables future migration of family members.

Much of the literature on Hispanic or Latino groups in the United States has focused on the importance of the family as a social institution. Further, the examination of the Latino family has centered on two specific areas of interest: familism or the "assortment of beliefs and behaviors associated with family solidarity and the extended family" (Baca Zinn 1994: 72) and the gendered division of labor within the family. The extended family, is often loosely defined for family groups in Latin America as well as in the United States, as a single household which extends vertically, containing three or more generations (Alcalay 1994). This definition however, is not a rule for all Latin American families in the United States or in the home country as the family may also extend horizontally, whereby cousins, aunts and uncles may also be included within a household. The definitions of the extended family often depend on the specific Hispanic group being examined. For instance, the literature on Mexican-Americans characterizes the 
extended family as one which includes a variety of relatives, including in-laws and even, compadres $^{1}$ (Baca Zinn 1994:72). The literature on Cuban-Americans, however, tends to emphasize the importance of the three-generation household, in which the grandparents serve an important role in providing childcare (Perez 1994: 106).

The majority of the literature on Nicaraguans in the United States has focused on the large groups which arrived in waves following the overthrow of the Somoza government in 1979. This concentration of the literature is understandable, given that the majority of Nicaraguans now living in the United States first arrived following the Revolution. However, the fact that the academic literature concentrates on the Revolutionary Period and its aftermath suggests, incorrectly, that Nicaragua had limited ties to the United States prior to its involvement in the war against the Sandinista government. In fact, the United States became directly involved in Nicaraguan politics nearly 150 years ago and has maintained close ties since. I will briefly outline this relationship, as well as provide information regarding Nicaragua's economy for the first half of the $20^{\text {th }}$ Century through 1963 , the date Aura Lila and her children left Nicaragua. I present this information in an effort to explain some of the structural factors which provided the impetus for relatively small numbers of Nicaraguans, including Aura Lila and her family, to migrate to the United States before the late 1970s.

\section{B. United States Involvement in Nicaragua}

The United States first became involved in Nicaraguan politics during the late 1840 s, when the various oligarchic families of Nicaragua fought each other for control of the entire country. The leading families from the areas of León and Granada hired U. S. mercenaries to fight each other. During the latter half of the nineteenth century, American companies established lucrative operations in Nicaragua, acquiring control of coffee plantations and lumbering outfits. Conflict arose when José Santos Zelaya assumed the presidency in 1893. Zelaya, a liberal from Granada, canceled a number of U.S. concessions upon taking office. The United States retaliated by deploying war ships to the region and supporting two rival families in ousting Zelaya. Zelaya resigned on December 25, 1909, marking the beginning of large-scale U.S. military influence in the region. U.S. Marines remained in an attempt to establish a government sympathetic to U.S. 
interests. Because there was resistance from various sectors, the United States increased its military presence, culminating with the outright occupation of Nicaragua from 1912 to 1933. From 1926 to 1933, the country remained embroiled in a virtual civil war, during which the U. S. government supported the more conservative oligarchic families.

American troops officially left Nicaragua on January 1, 1933, unable to defeat the popular guerrilla movement led by Agusto Cesar Sandino. Although briefly allied with the liberal faction of the oligarchic families, Sandino was assassinated by the National Guard. Anastasio Somoza García, who was installed as head of the National Guard by the U.S. Marines and is thought to have ordered Sandino's assassination, assumed the Nicaraguan presidency on January 1, 1937 through a military coup. With the Somoza presidency, Nicaragua once again became amenable to U.S. economic influence.

Although allied with the liberal families during the civil war, Somoza García was a staunch and loyal supporters of the United States. In return, the United States provided the Somoza government with economic and military support, including the continued training of the National Guard by the American military. The Somoza family amassed a large fortune during their stay in power. In 1958 , estimates of the family fortune ran from $\$ 60$ million to over $\$ 300$ million (Lethander 1968: 13). According to Lethander, the Somozas chose to invest most of their wealth in Nicaragua, which allowed them to increase their holdings (1968:14). Bulmer-Thomas (1987: 352) notes that their vast holdings, "included a wide range of enterprises which sold to local as well as overseas markets." The Somozas also attempted to invest in some social welfare programs, including the 1945 Labor Code, a national income tax begun in 1952, and a social security program enacted in 1956 . The period from 1933 to 1956 is considered by some Nicaraguans, including Aura Lila, to have been a relatively peaceful time in Nicaragua during which Somoza was able to maintain opposition at a minimum and enact some measure of economic reforms (Lethander 1968: 16). That opposition to the government existed is evidenced by the assassination of President Somoza García in 1956. His son, Luís assumed the presidency and remained in power until 1967, when he died of a heart attack, ${ }^{2}$ while his brother, Anastasio retained leadership of the National Guard. Critics of the Somozas have charged that the government practiced political persecution against its opponents, including torture and murder (Randall 
1991), and statistics show that despite limited reforms, the population of Nicaragua as a whole did not experience widespread prosperity (Walker 1991: 27-30).

The Somoza dynasty allowed U.S. companies to assume greater control of many of Nicaragua's industries and looked to the United States as a model for Nicaragua. Both of Somoza García's sons were U.S. educated and spoke English fluently. Their wholehearted embrace of U.S. culture was mirrored by other members of Nicaragua's upper classes. For a small middle class, the acceptance of U.S. culture was reinforced by a number of consumer goods available to those few who were able to afford them. Aura Lila and her husband, Juan, serve as examples of this small middle-class strata. According to them, their family lived comfortably in Nicaragua. Juan and Lila give their definition of comfortable by outlining the various appliances found in their home in Managua, including a refrigerator, stereo, television and well-made furniture. Moreover, with the advent of rock and roll music and television in the 1950s, U.S. culture became particularly attractive for those who could afford to buy radios and TVs.

\section{The Nicaraguan Economy: 1950-1963}

According to Lethander, the period between 1950 and 1963 witnessed an increase of Nicaragua's total labor force by 40 percent (1968: 120). The service and commerce sectors of the economy showed an increase of 102 percent for the same period, while agriculture and related interests showed a decrease (1968: 121-123). These figures highlight increased job opportunities in Nicaragua's cities and a decreasing of opportunities in rural areas. For the same period, Lethander notes that Nicaragua experienced a significant increase in internal migration from rural to urban areas (1968: 72-79). Using available census data for these years, he shows that Nicaragua's urban centers saw their populations increase by over five percent in 15 years. Using a definition for urban population which includes all population concentrations of 1,000 or more inhabitants, Lethander concludes that Nicaraguans living in urban centers went from being $31.5 \%$ of the total population in 1950 to $39.6 \%$ of the population in 1963 . This increase in population was particularly evident in Managua, the capital city. Between 1950 and 1963, Managua's population more than doubled to 234,580 inhabitants in 1963 , accounting for $20.8 \%$ of Nicaragua's total population. 
The increase in internal migration to urban areas resulted in greater job opportunities, particularly for women (Lethander 1968: 79-82). Opportunities for women included work in offices and domestic service. Between 1950 and 1963, the overall labor force participation of women increased by approximately 50\%. According to these data in 1950, $45.8 \%$ of women aged 15 - 34 participated in Nicaragua's labor force. By 1963, the percentage for this group of women had increased to $78.4 \%$.

Lethander's internal migration figures for the period between 1950 and 1963 explain the significant incresase seen in service and commerce sector labor force participation. There is no clear indication, however, that the jobs available to the large numbers arriving from Nicaragua's rural areas were high-paying (Lethander 1968: 121-3). These figures also show that labor force participation increased for women overall, while for men labor force participation decreased. Moreover, Lethander's statistics clearly outline the high rate of women's labor force participation dating from the 1950s. Nearly half of all women of childbearing age (15-34) were counted as participating in some form of wage-paying labor in 1950. Although census figures for 1950 must be accepted with caution to allow for a degree of error (Lethander 1968), the findings are significant when compared the to figures for other Latin American and Caribbean countries.

I present these figures in an effort to give the reader some idea regarding the economic conditions under which Aura Lila and her family lived prior to their migration to the United States. Unfortunately as Bulmer-Thomas notes, "[i]ncome distribution statistics are notoriously difficult to collect and even more difficult to interpret" for the Central American region from 1945-1960 (1987:197). I have therefore had considerable difficulty in presenting reliable statistics regarding the distribution of wealth in Nicaragua for the period between 1950 and 1963. Bulmer-Thomas (1987: 356) uses figures from a World Bank study of Nicaragua, conducted in 1953 , to showthat the top $1 \%$ of the population controlled $25 \%$ of the national income. The fortune amassed by the Somoza family in the decade following World War II placed them well within Nicaragua's economic elite, although the family's connections with the country's leading oligarchic families during this period (Bulmer-Thomas 1987: 133-135).

Aura Lila and Juan were not related to the oligarchic families of Nicaragua, and therefore did not enjoy the main advantage that such a family connection would bring: considerable land/ 
property ownership. Their combined family connections were few. One of Juan's older sisters was married to the President of Nicaragua's Banco Nacional and one of his older brothers was a prominent attorney. According to Aura Lila, these connections did not confer upon her family significant advantages. However, Aura Lila's older sister, Castalia, became the official hairdresser during the late 1950s for Doña Hope, Anastasio Somoza Debayle's wife. Although this connection did not confer upon Aura Lila's family any direct economic advantages- as it did for Castalia's family — she did benefit from this association, mainly through the expediting of miscellaneous bureaucratic affairs. Overall, though, Aura Lila did not classify her family as wellplaced within Nicaragua's elite. However, Aura Lila and her husband were also not among Nicaragua's poorest citizens and did live comfortably.

The significant changes in the Nicaraguan economy during the period between 1950 and 1963 affected Aura Lila and her family directly. In 1950, Aura Lila was 20 years old, single and living at home with her parents. According to her testimony, she had been working in her mother's beauty salon since she was 16 . She has said that once her mother died and she married and assumed responsibility for the care of her younger brothers, a nephew and two nieces, her income from the beauty salon was a great help to her family. While Juan held an office position with Esso during the early part of their marriage, he eventually left the position in an attempt to start a small business selling textiles throughout Central America. His attempt failed and it was shortly thereafter that he and Aura Lila decided to migrate to the United States. As will be seen in the narrative that follows, Aura Lila and Juan were concerened with maintaining a standard of living not available to most Nicaraguans. While they managed to sustain this standard for a few years, the changes in the Nicaraguan economy probably worked to make their aspirations seem less attainable. As job opportunities decreased for men, Juan's chances for finding better-paying work decreased- leaving Aura Lila's work in the salon as the prime source of stable income for the family by 1961 .

\section{D. "El perro que no sale a la calle no ecuentra hueso."}

My early efforts at uncovering the reasons which prompted Aura Lila and her family to leave Nicaragua for the United States in 1963, elicited short and tidy answers from my great-aunt. 
My initial attempt at introducing the subject came during our first interview, which relied heavily on a questionnaire I had formulated in an effort to gather basic demographic information. I administered the questionnaire to Aura Lila in her South Miami home on a weekday afternoon.

My great-aunt and I sat at the long glass-top dining room table, which sits just outside the kitchen. My Uncle Juan sat in the living room, which adjoins the dining area. He was watching television at the time, but managed to insert himself within the interview from time to time. He interrupted Aura Lila a few times in an effort, it seemed, to help her "get her facts straight." Juan's participation in the interview process was not contested by Aura Lila. I have decided to leave his commentary in areas where it helps to illuminate specific issues which might have influenced their decision to leave Nicaragua.

Aura Lila: "Why did I decide to come? Well because in Nicaragua my father used to tell me, you see, to come to the United States for my children because I might be able to provide them with a better education than in Nicaragua. And so my sister, Teresa had already come here [to the United States], to New York. And she sent word that I should come with my family. Juan came first. Then, I came with my three children and a niece. That's why I came, not because of any other reason because in Managua we lived more or less...well."

Juan: "We didn't miss anything. We had TV, refrigerator, we had everything."

Lila: "We had every convenience."

Juan [trying to talk over Lila]: "We had stereo."

Lila: "We lived very well."

It became clear to me that within this short exchange Juan and Aura Lila were trying to 
convince me that they had not been (and perhaps more importantly, did not consider themselves to be) economic or political refugees from Nicaragua. I got the sense that they wanted me to be aware that our family had been a respectable one, whose members had worked hard to live a relatively comfortable life in a country in which such a standard of living was the exception and not the rule. However, I was unclear why they might have taken such a chance at leaving the comfort and amenities they knew so well. I decided to try to focus on Aura Lila's memories of how she felt at leaving Nicaragua, in an effort to find a better explanation.

"I felt such unhappiness. I was leaving my country, my homeland. I was leaving my mother buried there. My mother had already died. I was leaving family still living there. I felt very unhappy."

I asked again why she came.

"Why did I come? Because of life's circumstances. Because I wanted to find a better life for my children. I was leaving behind everything that I had to find something better for my children. A better life than mine. Economically, well perhaps not. But for example, in education. So that they would be better able to prepare themselves for life. You see? Yes. That's the biggest reason for leaving Nicaragua."

I began to understand that Aura Lila and Juan's decision to move to the United States was fueled by a desire to improve their family's socioeconomic status. Although they had not mentioned this explicitly thus far, Aura Lila's mention of education as a means for her children to "better prepare themselves for life" alludes to a desire for greater prosperity. She discussed this issue more explicitly during our visit to Nicaragua in 1995 , proving my initial impression correct. I was able to approach the subject by asking her to reflect on her life in the United States, while 
she sat in a rocking chair in the home of a distant relative who lives in her hometown of Masatepe, Nicaragua.

"Look, I'm going to tell you one thing. When I emigrated from here to there, I didn't care for the United States. You see? But then I began to watch my kids grow and that country [the United States] was giving me everything, even though I had to work for it. That country made it easier for me to raise my children there. It wasn't like it was here. I made my money over there, and I was able to feed my kids and pay for the house in which I lived. It was easier.

It wasn't like over here, where things were getting harder. So, I began to feel affection for that country [the United States]. Here, it was becoming harder because life was harder. I bought a television, which no one had here, and it was so expensive! Because it was made in the United States. The clothes that came from the United States were extremely expensive. The shoes that I bought for my children that came from over there, were also extremely expensive. That's why it was hard. You would dress your children in the clothes made here and they would be torn up in no time. They weren't any good, or maybe that's just what I thought. Now if you bought some of the dresses they made here with lace and embroidery that they sold in the nice shops here, they were beautiful but you had to pay as much for them as the dresses made in the United States. They were so expensive, mama.

So if you wanted to buy a nice set of furniture, it would cost you your right eye. Even back then! It would cost 4,000 to 6,000 córdobas. ${ }^{3}$ We used to eat and everything. I'm not trying to tell you that we ever went hungry or anything like that. No. But it was hard because everything was made in the United States and it was extremely expensive over here. And if there was anything made with the same quality as something made in the United States, it cost the same. It was a very expensive life.

I used to make good money. Your uncle used to make good money. And we were living, well, mas o menos here. But I'll tell you one thing, I was never able to save one cent while living here [in Nicaragua]. Never. I lived comfortably but don't think I had 
money stashed away in a bank somewhere. I don't ever remember having any money saved away in a bank. Now, in the United States I made very little when I first started to work. I made very little, but we were all right. Here, life was very expensive. But over there it wasn't. In a way, life in the United States was easier. I could buy clothes for the kids. Back then, you didn't earn so much but you could buy a dozen eggs with fifteen cents and a liter of milk for twenty-five! So, even with the little that you earned, you lived well.

Everyone in the United States, no matter how poor they are, has their own television set. You pay for it little by little, but you're able to get by."

Within this passage, we begin to see that Aura Lila and Juan were not impoverished individuals who needed to find a place to live or more food to feed their family. In fact, both of them worked and earned a regular income with which they could afford to live comfortably. Juan worked as a bookkeeper for a family who owned three Esso gasoline stations. Aura Lila ran a hair salon out of the home she and Juan rented on a busy street near Managua's commercial district. With their combined salaries, Juan and Aura Lila could afford to rent a house, buy comforts not afforded by most Nicaraguans, and hire a small staff of domestic servants to help in running the household and caring for their children. Yet, it is also clear that Aura Lila was not completely satisfied with the lifestyle she and her husband were providing for their family.

What could they have been lacking? According to the popular imagination, immigrants who decide to leave their homelands are seeking the opportunity to live the "American dream," a life filled with innumerable consumer goods and products. However for Aura Lila and Juan, this dream seems to have already been fulfilled in Nicaragua. Why take such a risk to leave behind everyone and everything they knew? Portes and Rumbaut cite a number of studies which have found that contemporary international immigrants tend to have higher levels of income and education "in comparison with their homeland populations" (1990: 10-11). They stress that the very poor are rarely in a position to accumulate the resources for international migration. Therefore, contrary to popular and some academic opinions, the immigrants arriving in the United States after World War II have not been exclusively made up of "destitute and huddled masses 
yearning to be free." According to Portes and Rumbaut, what seems to be driving such individuals' decisions to migrate is a "gap between life aspirations and expectations and the means to fulfill them in the sending countries" (1990: 12). Their assertion seems to hold true for what we know thus far of the reasoning that went into Aura Lila and Juan's decision to emigrate.

Aura Lila's statement that everyone in the United States owns a television set can serve as a point of departure in analyzing the aspirations she felt might be fulfilled by migrating. Owning a TV was not the objective. As we've seen, she and Juan were able to purchase one, albeit at a considerable expense. What is not explicitly articulated within that statement but remains evident regards the nature of the opportunities available to everyone in the United States. In a country where even the poorest of the poor owns a television set, poverty begins to take on a different meaning. The poorest individuals in the United States could not compare to the poorest individuals living in Nicaragua or other developing nations. Thus according to this logic, immigrants entering the United States have a higher chance of achieving the goal of social mobility than their contemporaries remaining in the country of origin.

This is especially the case if we consider that neither Aura Lila nor Juan owned any land or property in Nicaragua. According to Aura Lila, her father Inocencio had owned the house and land on which his family lived in Masatepe during Aura Lila's early childhood. However, Inocencio sold the land in order to move the family to Managua. They were not able to buy a home and thereafter rented the houses in which they lived. My uncle Juan, one of 14 children, did not acquire any land upon reaching maturity. Therefore after they married, he and Aura Lila remained renters until they settled in Queens, New York.

Aura Lila and Juan both completed the equivalent of a ninth grade education when they left school. Juan found work in the office of an import/export firm owned by family friends. Before they married, Aura Lila worked mornings in the Statistical Office of the National Health Center and afternoons in a hair salon her mother ran. She says she gave the money she earned to her parents, to help with household expenses. Once she married Juan, Aura Lila continued to work in the hair salon. Later, Juan was offered the position by the family who owned the Esso gas stations. The owner of these stations was a wealthy customer who frequented Aura Lila's hair salon. 
By their own account, Aura Lila and Juan did not consider themselves to be members of Nicaragua's elite. Although they were clearly better off than the vast majority of Nicaraguans, they did not move in the circles of Nicaragua's largest land-owning families. Their education and work history indicate that their lifestyles approached a middle-class standard. This standard was difficult to maintain in Nicaragua, however.

According to Aura Lila, she and Juan once tried to buy their own home, but found the process overwhelming. The owner quoted an initial price, then increased it and expected a payment of almost half the total cost. She contrasts this with her experience in Queens, New York, where she was able to give a down payment of $\$ 500$ dollars and pay less than $\$ 200$ dollars a month for a two-story house with a backyard. This anecdote indicates that Aura Lila and Juan held certain middle-class aspirations - especially, owning a home - which could not easily be fulfilled in Nicaragua. The United States seemed to offer them the allure of stabilizing their middle-class position. However, this determination does not appear to be a rational calculation made by either Aura Lila or Juan.

Economic theories of migration often portray families as groups seeking to maximize their expected income, as well as to "rationally minimize risks" within the labor market. (Massey et al. 1993 :436). Yet Aura Lila contends that the decision to migrate was not fully motivated by economics. Rather, she and Juan carried an abstract notion of bettering the conditions for their family. While Aura Lila's conception of "economics" probably differs from a more standard academic definition, it remains important to use her own words in reaching an understanding of the reasoning which led her family to migrate. Her words offer an example of individual agency within the process of international migration. Moreover, her words are rooted in a context which clearly emphasizes the importance of the family within the migration process. Thus far, we have seen that Aura Lila was advised to migrate by her father, and that she based her consideration upon the well-being of her children. Although we have not yet examined her husband's role within this process, further investigation of Aura Lila's migration history must concentrate on her family as an important unit of analysis.

Analysis of the family highlights the interplay between structural forces and individual agency within the process of migration. It provides us with an understanding of migration as a 
complex of social networks (Portes and Bach 1985: 10). According to Boyd, migration research which emphasizes social networks in migration,

"particularly those linked to family and households, permits understanding migration as a social product - not the sole result of individual decisions made by individual actors, not as the sole result of economic or political parameters, but rather as an outcome of these factors in interaction" (1989: 642).

Further, Boyd notes that families "transmit cultural values and norms which influence who migrates and why" (1989:643). For Aura Lila, the basis of her family's migration rests largely on two points: 1) her father's insistence that she move for the sake of her children and 2) one of her sisters was already living in the United States. She emphasized these points during another conversation we held while in Nicaragua, which included a family friend who contemplated migrating to the United States.

"My sister Teresa used to call me all of the time and tell me to come. She used to call me to come [to the United States]. So, I told my father, 'Imagine, my sister has me crazy. She keeps telling me that I should go.' And my father told me, 'I'm going to tell you one thing. I took all of you out of Masatepe because you weren't going to amount to anything there. That's why I brought you here [to Managua]. Now, I'm going to tell you another thing. The dog that does not venture out into the street will not find a bone. You have to go so that you can make a better life for your children.' So that's why I decided to come, to bring my three children and your mother. I count her as my own daughter. You see?

And I tell you, my oldest son who lives in New York, who works for an importing company there. He always comes to visit us in Miami and he tells me, 'Mama, I thank you and my father for bringing us here." "

The previous excerpt serves to illustrate two important theoretical points. The fact that Aura Lila's older sister, Teresa, had already settled in the New York, provided Aura Lila with a 
known and trusted contact abroad. The significance of such personal contacts within the process of international migration has been emphasized by Massey et al. (1987: 5-6) and others (Piore 1979; Bohning 1972). The importance which Aura Lila placed on her father's advice that she should move for her children's sake as he had done in the past, reinforces Boyd's position (stated above) regarding the transmission of cultural values influencing migration. Within Aura Lila's family, migration as a means of bettering the family position had become an integral part of the family's cultural fabric. Inocencio urged his daughter to move her family as he had done when he moved his wife and children from the small town of Masatepe to the capital, Managua. The effect of this family history of migration resulted in a situation where seven of the Casco siblings (including Aura Lila) migrated from Nicaragua between the early 1960s and the early 1970s, prior to the Sandinista Revolution.

Interestingly, Aura Lila does not mention that she ever questioned her father's rationale for advising her to migrate. Her unquestioning acceptance of his advice has much to do with her belief that in matters of importance children should not question their parents, who invariably know better. These beliefs about the relationship between parents and their children, which have been expressed to me on numerous occasions throughout my life, will be examined in depth in the next chapter. What I would here like to note is the importance which she invests in her father's role within the decision-making process. According to Aura Lila, her father seems to have sensed that his grandchildren's lives might not turn out to be as comfortable as the lives of his children had been. In effect, she assigns her father to the role of "seer," who anticipates eventual evils and hardships for Nicaragua.

During the lengthy conversations we held while in Nicaragua together, Aura Lila would launch into long and ardent denunciations of the ousted Sandinistas, who still held some measure of political power, primarily through the labor unions. Sergio Ramirez, the well-known Sandinista author and former vice-president of Nicaragua, was running for mayor of Masatepe then, and more than a few walls and houses were covered with his portrait, calling for support in the elections. After lecturing me on the many abuses committed by the Sandinistas, Aura Lilaindulging in more than a considerable amount of hindsight— said that looking back, she had had 
no alternative but to leave given the turmoil that awaited Nicaragua. When I asked her if she had had an indication of the war which would not take place until 16 years after she left, however, Aura Lila answered that she did not.

"My kids... Do you think if I had stayed here with all of those guerrillas there have been... Who would my children have become? What were my children going to study here? Where was I going to work? Where was Juan going to work? If I didn't move from here, we might have stayed here and we might have been eating dirt.

What was I going to do here? I had to go. I didn't see it. But my father did. My father used to tell me, 'Get out of here. This country of ours is not good for anything. Over there [in the United States], you can do something for your kids.' That's what he told me. And I can't forget the phrase he used. He told me, 'The dog that doesn't go out into the street will not find a bone.'

That's really why I left. Maybe, I might never have gone because I couldn't see further ahead, what was going to happen. There weren't those... those movements against Somoza. No. The whole country was calm. You see? It was very nice to live in Managua back then. But my father started to tell me, 'Go, go. You're kids are going to be no one here.' And so I said, 'I'm going to go.' And that's why I left."

This portion of Aura Lila's narrative clearly introduces the political ideology shared by Aura Lila and her family. Obviously, Aura Lila believed that Nicaragua was a peaceful and prosperous country before she left. She has often said that the years during which the Somozas were in power were the best in Nicaraguan history. She also claims to have no direct knowledge of atrocities carried out explicitly by the Somozas. However, she does seem to suggest that the country was mired in a historical process of deterioration which although not evident at the time, came to pass with the Sandinista victory over Somoza. According to Aura Lila, the Sandinistas "ruined" Nicaragua.

"In the first place, when Sandinismo took over, what did Sandinismo do? They took 
houses away from the owners. There was no work for those who were not Sandinista. That's how the country became poor. That's why so many people started to emigrate to the United States, because Sandinismo left nothing here. They stole everything... what was left in this country. So, what were we going to do here? Sandinismo was only for the people who fought on their side. They gave everything to them and their families. They didn't care about the rest of the people who didn't get involved. But they stole their houses. They stole land, they stole businesses, they stole whatever they could because no one was supposed to own anything."

For Aura Lila, the Sandinistas personified the evils of communism, where "no one is supposed to own anything." In her opinion, the greatest affront that the Sandinistas committed against Nicaraguans was to steal land and redistribute it amongst their supporters. She has also defended the Somozas as being nothing more than wise investors, who wanted progress for all of Nicaragua. Such statements clearly point to her middle-class convictions. While I will not take the time to comment on our differences in political opinion here ${ }^{4} \mathrm{I}$ feel that such information relates to her migration experience. Once again, the importance of the family's cultural valuesin this case, their political beliefs- becomes evident. If we examine Aura Lila's family background, we might begin to understand her vehement political position and her father's repeated exhortations that she migrate. More importantly, we can begin to see how such beliefs might have influenced her decision to migrate to a country she had never visited.

As noted earlier, Aura Lila's father had been an officer in the civil war which lasted from 1926 through 1933. Inocencio fought on the side of the conservatives against the liberals who had allied themselves with Agusto C. Sandino in an effort to end continued U.S. intervention in Nicaragua. Hence, his favorable opinion of the United States and the lifestyle it offered. Given that her father felt this way and that she respectfully observed his opinion, we can understand Aura Lila's opposition to the Sandinistas. Her support of the Somozas is less clear-cut. While she claims never to have been a somocista due to her conservative position, she also claims that she did not ever involve herself directly in the country's political process. Interestingly, Aura Lila's impressions of life in Nicaragua under the Sandinistas were formed without the benefit of 
first-hand experience. After two brief visits to Nicaragua in 1972 and in 1978, Aura Lila would not return to her home country until our visit together in 1995.

I would now like to turn to the process of migration itself. Thus far, we have not seen my uncle Juan as an important part of the migration history. Anyone who knows my great-aunt would agree that she assumes a central place in her stories which tends to overshadow most everyone else. However, Aura Lila and Juan did make a mutual decision to migrate with their children. The course of their eventual move to the United States mirrors the experiences of many immigrant families. Juan left Nicaragua first, in 1962, in order to find a place to live and a stable job where he could earn enough to send for the family. Aura Lila describes how they reached a decision this way.

“He didn't want to come. At first, he didn't want to come because he was afraid... Eh, how should I explain it? What was there here in the United States? He didn't know what the United States were like. He had more or less of an idea but he was afraid of what he didn't know.

I was the one who always wanted to come, you see? I had wanted to come to the United States my whole life. But that was when Juancito [her first son], was small that I wanted to come on my own. Afterward, since my sister Tere was living here in the United States and she used to tell me to come, to come, so I began to have that desire to come over here. But since he [Juan] was making good money [in Nicaragua] and I was also making good money, we didn't. You see?

So, what happened is that he stopped working. He stopped working where he was working and tried some other things. But he didn't like what he was doing. He used to go to San Salvador and leave merchandise over there. And he didn't like doing that. So he said to me, 'I'm going to go to the United States.' 'Go,' I told him. I was going to give birth to Ingemar [her third and youngest son]. So, he decided. But I had to push him! I put him on that plane and I shut the door!

I'll tell you one thing. I thought about staying in Nicaragua, for an instant. But I had five children to take care of by then. I had my own three and your mother and her sister. 
That was five. It wasn't just one and they were all kind of young. So, I said, 'I'm going.' And that's how it is that I came here. Maybe if he had come and I had only had Juancito, maybe I wouldn't have come I could have stayed there [in Nicaragua] with my son. With one. But with five? There were already five kids."

The reader will be struck by how Aura Lila makes light of Juan's role in the decisionprocess. According to her, she forced him to go. Yet we also see that the decision to migrate is definitely influenced by the change in Juan's occupation. He had gone from working in a secure position as a bookkeeper to transporting merchandise in El Salvador. Once he realized that he didn't care for this line of work, the option to migrate became more viable. Aura Lila, as we have seen, says that she thought about migrating after her sister, Teresa, moved and urged her to follow. Although she makes much of her husband's reluctance to migrate, Aura Lila waited to come to the United States until Juan moved and established a home base for the family.

Aura Lila also provides evidence of a long-standing martial conflict between Juan and herself. The admission that she thought for an instant about staying in Nicaragua after her husband had first gone, came after four years of interviewing. This topic will be explored in more depth within the next chapter. However, this example serves to illustrate the realities that Aura Lila faced and was forced to accommodate as she decided to join her husband in the United States.

By the time Juan departed Nicaragua in March of 1962, Aura Lila knew that she would join him . She remained in Managua for a year, working in the hair salon a few more months and then, sold the business. With the profits from the salon, she was able to maintain herself and the children until she was able to sell all of the family's belongings. Juan, meanwhile, had been able to find a job in a lamp manufacturing factory and had moved in with his sister-in-law, Teresa, her husband and children. Aura Lila left Nicaragua in April 1963, a little over a year after Juan's departure. Upon arrival, she and the children moved into Teresa's apartment, located in Manhattan's Upper West Side. When she arrived however, she found that Juan had lost his job due to factory layoffs and was collecting unemployment.

According to my great-aunt she did not look for work until after she had been here for 
seven months. She felt, she has said, as though there was no one else to watch the children, as all of the other adults were working. It is clear though, that from her perspective, the issue of not having enough money to support the children was extremely important to Aura Lila. She decided to go out in search of a job in November 1963. I have decided to use parts of Aura Lila's narrative here which were recorded during our first interview together. The narrative begins with her description of how she felt upon arriving in the U.S and what she felt about her first year here.

"My first impression of the United States was... [Pauses.] ...a feeling that I could not get my bearings. I felt... I didn't feel comfortable, I didn't feel right. After coming from something so different, from such a small country to come to something so big. To see those beautiful shops. Well, my first impression was a good one. But I was totally disoriented. I was disoriented, you see, for a very long time. I couldn't... It took me a long time to become accustomed to the multitudes of people. They'd run from one direction to the other. And you don't even know where you're going, yourself! You don't know who you are and no one knows you either. Yes, that's what it was like. That's what it feels like when you've just arrived in this country. What's more, I didn't know any English. I arrived in New York at that time and almost no one spoke Spanish. It was hard. Yes. Honestly, the United States made a very big impression on me when I arrived.

My first year in the United States was a difficult one. It was very difficult. I cried a lot. I came here with three children and my niece. When I got here, I found out that my husband was collecting thirty-five dollars a week [in unemployment compensation] because he wasn't working. When I arrived, I had to live with my sister and, we didn't have to pay rent. When I saw that we were not going to make it with what he was collecting, I went out to find work.

I came here with Ingermancito in my arms, recently born. Juancito was nine years old. La Chilito was seven. And your mother, who was about sixteen, I think. Fifteen, sixteen. Your mother was sixteen when we came. ${ }^{5}$ You see? And when I came and saw that your uncle was making thirty-five dollars, I almost went crazy! We didn't even have 
the money to buy socks for the kids. Oh no, I said. This is ending right here. And I took the train, without speaking English, without knowing anyone, without knowing where I was going.

I took the train... the Manhattan line... going on Amsterdam. The one that ran along Amsterdam. I got to Grand Central Station, that one. I got to Grand Central. That's where I got off. There were some factories there, owned by Jews. And without knowing... But look at how people are. One has an idea, more or less, because over there[in Nicaragua] they teach you English in school. Right? But it is not extensive English, and the pronunciation is completely different from the one here. Everything, everything is confused. Everything is confused. And I went to this Jew and he said to me, he said to me in English and I understood him somewhat. What did I want to work in? And I told him that I would work doing anything. So, he told me to come back the next day.

I knew some words. And he told me, Tomorrow. O.K., I said to him. But then after I had the interview with him, this Jew, I found my sister's husband on the train. And he said to me.... He was very surprised to see me all alone, since I had never been on a train. And what are you doing here? he asked me. Looking for work, I told him. So then, my sister took me with her to work the next day. I couldn't go back to the Jew again."

Once again, we find Aura Lila assuming a heroic role within the story. Yet, she has described the months living in her sister's apartment as difficult ones, given that there were four adults and six children sharing the space. She says that she felt compelled to do something because Juan had been having difficulty in finding another job. Therefore, she decided to take her chances alone to see what she could find. The fact that her brother-in-law found her riding the train one day and that her sister took her into work with her the next, suggests that she was acting on impulse unknown to the other adults. There is also the suggestion that venturing out into the city alone in search of a job might have been too impulsive for a married woman, who knew very little of the city's geographical layout and the language. Therefore, her sister became instrumental in finding her a job, as well. Here, we find a specific instance of the migrant 
network operating at the individual level.

For Aura Lila, the opportunity to work with her sister allowed her to quickly gain knowledge of the clothing factory where she would begin as a seamstress. We also see that by working closely with her sister, she was able to acquire the skills necessary to advance her position within the company and to earn more money. In the narrative that follows, Aura Lila describes the process of she inherited her sister's position as forelady, which took a number of years.

"She was the forelady there and she took me, and that's when I began to earn 42 dollars my first week. That was a lot of money. You see? With 16 dollars, I could go to the supermarket and buy lot of food that would last for up two weeks sometimes. I stayed there working as a finisher. ${ }^{6}$ Later, I became the receptionist.

Well, but this man, the owner of the factory, when I was working there, he wanted to make me the forelady of another factory that he owned, "Regents." Because he owned two factories, "Tischler and Benkel" and "Regents." He wanted to send me to "Regents," you see? But then I asked him how much he was going to pay me. He told me 60 dollars. No, I told him. I was going to go and assume so much responsibility. I already spoke a little bit of English, because I was taking classes with your mother. No, I told him. I'm not going to take 60 dollars, I told him. So, I didn't go. I stayed there. But I stayed and when your Tía Teresa, who was the forelady, when she kept account of everything, taking account of what all the women earned, all of the work they did.... So, she would take account of all the work and on Fridays she would give the bookkeeper a sheet for each worker so that he could write the checks.

You see? Then she.... I watched her.... I watched what she was doing and it used to take her a long time. Then I would come and take the sheets on the workers, the work that they did and I would work on them. So, I started to work on the accounts and everything. When my sister died, ${ }^{7}$ right, they said that the only one who could become the boss was me. The rest of them, who had been working there for years, Puerto Ricans, asked for the position. And they didn't give it to them. No, they told them, not any of 
you. Because none of them knew as much about grammar and arithmetic like she does. They didn't know. No. So they gave it to me. That's why they gave me the position, because I used to stay with my sister and do the work for her. While she went over the work that had been done, I took account of the hours. So much so that when I became the forelady, it was nothing to me. I could do that with my eyes closed, all of the work and I knew how to do it perfectly."

Shortly after Aura Lila started working at the factory with her sister, Juan found work in the offices of a local import/export firm. Aura Lila says that with both of their incomes, the household finances became much easier to manage. Nine months after her arrival, Aura Lila's sister and her brother-in-law bought a house in Queens. They invited Aura Lila and Juan to move in with them. They all moved to the relatively quiet suburban neighborhood of Corona. Aura Lila, Juan and their children rented the upstairs portion of the house from her sister. She says that they liked living in the house much better because "they had never been accustomed to living in apartments" and the "neighborhood was much nicer than Manhattan." Two years later, Aura Lila and Juan were able to save enough money to buy their own home in the same neighborhood. Nearly three years after Aura Lila and the children had arrived, they seemed on their way to achieving the middle-class stability that had eluded them in her home country. 
${ }^{1}$ The compadrazgo system of fictive kinship provides for family ties through the practice of godparentage. It is often a reciprocal relationship where the compadres agree to act as surrogate parents for the god child in return for some benefit derived from their ties to the child's parents (Baca Zinn 1994).

${ }^{2}$ Luis Somoza maintained presidential authority despite the election of two "puppet presidents" (Walker 1991).

${ }^{3}$ This would be the equivalent of approximately $\$ 600$ U.S. during the late 1950 s to early 1960 s.

${ }^{4}$ When explaining her political position, Aura Lila has often said to me, "I know how you think!" She is referring to my stated sympathy for the Sandinista Revolution, a topic which we have debated on numerous occasions.

${ }^{5}$ Aura Lila is mistaken here. My mother was nearly 18 years old when they arrived.

${ }^{6} \mathrm{~A}$ "finisher" literally completes the sewing of a man's suit. Finishers were the last to handle the garment being produced.

'Teresa Cuadra, Aura Lila's sister, died of breast cancer in 1970. 
Chapter III: "Yo te cuento todo esto para que veas como es la vida, mama."

In this chapter, I would like to more closely examine Aura Lila's life within the context of the family. Specifically, I would like to focus on the portions of her narrative concerning marriage and motherhood-both central themes in my great aunt's life. By focusing on some of the details of Aura Lila's life with my Uncle Juan and the raising of five children in a foreign country, I seek to illuminate the central importance of gender within her life and its influence on her immigration experience. Although the events described by Aura Lila were unique in that they were time-, space-, and culture-specific, they can be useful in understanding some of the circumstances surrounding immigrant women who identify as wives and mothers. Moreover, Aura Lila's narrative regarding her ideas about the changing nature of gender roles provides insight into the belief system with which she grew up in Nicaragua. This text demonstrates the complexity of the gender dynamic within the life of a woman who has moved from one cultural environment to another.

For this section, I also interviewed Aura Lila's only daughter, María, age 42, in order to provide added perspective to Aura Lila's self-representation as a mother. By adding Maria's narrative, I was able to show some of the contradictions between Aura Lila's perceptions of herself as a mother and how María experienced being raised in a household which seemed different from those of "American" children her age. I was also able to identify the importance of gender in my cousin's life and her feelings that being a woman has often constrained her opportunities. Many of these feelings center around disagreement with how her mother raised her and the expectations she felt her parents held—and at times, still hold—for her.

For Aura Lila, the subject of marriage is one rife with contradictions. She remembers her parents having had a "beautiful life" together. Despite memories of her parent's loving marriage, she says that watching her older sister, Juana-my biological grandmother-struggle through two bad marriages left her with a strong desire never to marry. Yet, Aura Lila readily accepted responsibility for care of an extended family, which included her father, younger brothers, nieces and nephews at a relatively young age and ultimately accepted the cultural expectation to marry. A variety of factors may have shaped Aura Lila's early rejection of marriage, including the fact 
that her first boyfriend was not deemed an acceptable suitor by her parents (mentioned by Aura Lila) and that as a woman, she was not able to pursue a professional career (mentioned by María). Yet, Aura Lila's story serves to illustrate the importance of gender in that despite her rejection of marriage-a primary expectation for women in Nicaragua and elsewhere in Latin America-Aura Lila subsumes her individual wishes and attempts to reinforce the roles which seemed so confining to her as a young woman in her daughter.

I began by asking Aura Lila about her thoughts on how she had experienced married life. It took a number of sessions, some having had a good deal of time pass between them, to elicit the contradictions which formulate Aura Lila's thoughts on gender. During the time it has taken me to write this thesis, I have married, borne a child and have undergone a separation, which will ultimately lead to divorce. Many times, as I recorded Aura Lila's words in late 1997, I found her struggling to accept my domestic situation-usually, without referring to me or my family situation directly. The words she spoke during these interviews differed dramatically from her initial admonitions to me that I must stay with my husband, no matter what, for the sake of my infant daughter. It was often difficult to separate my personal feelings which arose during our "private" (non-recorded) conversations and while reviewing Aura Lila's narrative for this text. The generational differences between us became quite clear when I realized that although Aura Lila claims to recognize marriage as an institution imposed by society and more locally, parents, she accepted this imposition and seems to have worked to ensure the survival of traditional gender values.

L: Well, you always say that you might not have married if you hadn't ended up taking care of so many people. Right?

AL: No. No.

L: But, I wanted to ask you about... how you view... the life you've led with your husband. 
AL: How I view it?

L: Now, but also everything you've experienced in the past. From the time you married to now.

AL: Now. In the beginning. In the beginning. Yes, at the beginning it was hard for me.

L: Why?

AL: Because he was an enamorado.

L: What was he in love with? What do you mean, enamorado?

AL: He was in love with every woman. Yes. Yes. [L: laughs.] You're going to record that and he's going to get angry! But he was a womanizer. Yes. I suffered very much. I suffered.

L: Did you ever think to leave him?

AL: I thought about it. I thought about coming over here [to the United States] with Juancito. But when I went to the American embassy in my country, I saw a man I knew who worked there. Juan knew him also. And when I told him that I wanted to come to the United States he told me, If you don't have your husband's signature granting permission for you to take the child, you can't take him. So, what did I do? I returned home and stayed there. I took it.

L: Does he know this?

AL: Who? 
L: My uncle.

AL: I told him a bunch of times! [L laughs.] Oh yes, yes, yes. I did.

L: You know that you don't have to tell me anything you don't want to or that you don't want me to record. If there is any question you don't want to answer....

AL: But why? There's nothing wrong with what I'm telling you. These things are all part of life. You see? They are part of life and as I've explained to you, I didn't want to marry because of what I'd seen my sisters go through.

L: You told me that your sister, Esperanza, had some trouble with her husband in Nicaragua, so she moved with him to New York.

A: Problem in Nicaragua? Yes, he was another womanizer and he was already married to her. You see, it was only after they married because when they were seeing each other, there was no inkling. But after he married, he wanted to continue going around like a single guy.

L: So you are telling me that my uncle used to go around with other women before and after you married?

AL: I didn't figure anything out before; it was only after we married that I found out. Before, I didn't know about because I didn't really see him all the time or anything like that. The only time I went out with him was when I went to the movies or when we went to mass. And I always had to take someone with me [a relative]. I wasn't even allowed to go out the door by myself. They probably thought that someone might do something to me. They probably should have worried about what I would do to someone! 
In this initial portion of the narrative, Aura Lila begins to describe the conditions under which she was socialized as a woman. To a degree, these conditions can be identified as part of a larger reality for many women of Aura Lila's generation who grew up in Latin America. This situation, that of the mujer encerrada, or woman confined to her father's house until marriage, has its roots in Roman law, which specifically denied women the authority to transmit legal power to her children (Pomata 1996: 47). Under Roman law, women could create only the natural bonds of kinship devoid of the privileges attached to the creation of legal kinship —or agnatio - solely reserved for men (Pomata 1996: 46). Women therefore remained citizens of lower status, dependent on men for privileges, which were extended by fathers or husbands.

Spanish law borrowed greatly from Roman civil codes in perpetuating patriarchal values, particularly through patria potestad, or rule of the father. However, when transferred to the colonial context, Spanish law strengthened women's positions relatively with regard to guardianship over children for widows and separated mothers (Ramos-Escandon 1996: 279). The effect of such strong patriarchal laws helped to perpetuate specific social ideals for women which centered around the roles of wife and mother. Early on for Aura Lila, these ideals-which were, by her account, still very much prevalent in Nicaragua while she was growing up-became somewhat problematic for her.

As already noted, she claims that her sister Juana's ill-fated marriages prejudiced her against marriage early on. Yet, because she had assumed responsibility for caring for a large extended family while still single, she says she knew she would eventually have to give in and marry. We should also note the importance of hindsight in interpreting Aura Lila's narrative regarding this topic. Aura Lila saw two of her sisters experience problematic marital relationships-Juana, my grandmother and Esperanza, her younger sister—only to experience some of the same problems with her own husband, Juan. Yet, as she recounts her relationship with her first boyfriend, there is no hint that she held the mistrust of husbands, which she relates so often.

L: I wanted to ask you about that. You told me that your mother and your father had a beautiful life together. But then you say that what you saw your sisters experience made 
you feel that you never wanted to marry.

AL: I was traumatized by what I saw. It bothered me very much.

L: But didn't you ever think that maybe, someday, you'd meet someone ... because you always talk about your father.

AL: He was a beautiful person.

L: Did you ever think that you might meet someone like him? Did you just resign yourself to ...

AL: Look. Sure, of course. I already told you. I had a boyfriend, my first boyfriend. I loved him. I adored him and was affectionate with him. He was everything to me. Look, he was the kind of guy that.... When I went to the movies with him, believe me, he was extremely respectful. I never found another man to be as respectful of me as he was. I loved him very much. What more can I say? I loved him, but because he drank...

L: He drank?

AL: He drank. You see, he was older than me. Not by much. Not by much. He was maybe five years older than me. We met at school. He taught me how to play the drums because I was in the school marching band. [L: Oh yes.] Yes. So, he would stand behind me and take my hands and show me how to play. And that's when I began to like him. That's how it all started. But he drank. He started working while I was still in school. They used to hit me because of him. They hit me a lot. They didn't want me to see him.

L: Your parents knew that he drank? 
AL: Well, of course. They knew who he was. People used to tell my parents about him. That's why my parents didn't like him. But I would have preferred a drunk to a womanizer like your uncle.

L: Didn't my uncle drink, too?

AL: No. No. He drank a beer here and there, yes. He drank more after we got married and he started going around with other women and everything. He used to go around with other women. I worked in the beauty salon and he used to throw our money away. [L: But did you ever consider divorce? I mean, I mean... well, you tell me. ] Yes, I thought about it. I told my sister Castalia, who lived across the street from me. I had Juancito, then, and with Juancito alone, I could have gone to the ends of the earth. Yes, I thought about it. And so, I told her, "Look, I'm going to end this." I told her, "I'm going to leave Juan." Do you know what she said to me?

"Don't do it," she said. "You're young. And in Managua- I'm talking to you about Managua, which is completely different from here. [L: Right.] Here, you can choose. In Managua, there is a little group you have to choose from. It's not like it is here. So, she said to me, "Look, you're young. You're attractive. You're going to end up being seduced." That's what she told me. "Then what will happen? Today, you'll accept this one and then, tomorrow another, and you'll end up having a child from every man you fall for." So I said, she might have a point. I'm going to stay with this one. I couldn't leave the country. I couldn't leave the country.

L: What about if you were divorced? Would you have had custody of the child or not?

AL: What do you mean if I were divorced?

L: When a couple is divorced, one of the parents usually retains custody. I don't know 
what it was like over there. I don't know if the father was given custody.

AL: No, they would give the child to the mother. [L: That's what I meant.] But the father retains rights over the child. I would have had to contend with him for anything relating to the child, right? [L: So, what happened? You stayed there and did you tell him.... I stayed there. Oh yes. I stayed in the house with him. I didn't say anything to him. I stayed quiet. Because everything I ever tried to do came out wrong. So what did I do? I stayed there with him. I kept working in the salon I had. I took it, I always took whatever he gave. When didn't I? When he wanted to come to the United States, I didn't want to. I didn't want to come anymore. [L: OK, OK. Continue.] I didn't want to come. I said, no. But he used to call me all the time to come. He used to call me to come. Then Juancito, the oldest, said to me, "Let's go to where my father is." He kept telling me. He had me crazy. And then I thought, this boy is going to get worse. He already had a strong character. Juancito. He was rebellious even as a little boy. I thought, if I don't do it he will become even more rebellious. So, I came. And in all honesty, once we got here things were better. He changed. It seems that this country fixed him. He didn't go around doing what he used to. But even though, he used to drink and run around with women, he never failed to bring money home for the children, his children. Yes. We used to live very well.

L: You told me that there were no good men, right?

\begin{abstract}
AL: There are no good men. It's a lie. My father told me that they are born with mal levadura.
\end{abstract}

L: What is levadura?'

AL: Levadura, well, maybe he meant that they are born with bad thoughts. You see? I told you that my father had been good to my mother, but when he was single he ran 
around, too. He had children with other women. He drank. And he told me all of the things that he used to do. Yes. Once he married my mother, he was good. Very affectionate.

Now, I think that women will reach a point where they will choose not to marry. No. In all honesty, if you want to have children nowadays, you can just have those little things injected into you. And there you have a child. You don't need to have a man who will be bothering you. Because in reality, you are the maid, you are the children's nanny and you are his keeper. You have to clean. You have to cook. And him? He works, comes home and that's it. And you have to work, too. You have to work and you have to do everything else. You see?

So, there will come a time when women will simply not want to marry. Yes. Or they will just live together. That's how it is. We are seeing all of these things in the world today. So many things. And the woman no longer wants to put up with the man. No. The old days are over, the days when your grandmother put up with so much from her husband [my biological grandfather]. Women today don't want to put up with it. Although I used to work. I could have supported myself, but don't think that I was going to be having the time of my life. When you have a lot of children.... That's why I tell you, "Hija, if you can stay with just this one, do it." [She points to my daughter, Mia, and laughs.] With this one you can go to the ends of the earth.

Aura Lila raises a number of issues in the preceding narrative, chief of which is the perception that she was trapped in her situation. She says, “...everything I ever tried to do came out wrong," in considering her attempts to leave Juan. Legally, she was unable to take her son to the United States without Juan's permission. Perhaps more devastating to Aura Lila was the conversation with her sister Castalia, who counseled her to stay in her marriage lest she become a shameful woman. This shameful woman, the mujer fracasada described by Esperanza Hernandez in Translated Woman (Behar 1993: 156-64) is the antithesis of the proper wife and mother-a woman without a husband to support her and the children, who will take up with any man who will have her. According to Castalia, Aura Lila risked becoming such a woman by 
leaving her husband. Although Aura Lila gives no further explanation as to the basis for Castalia's advice, there seems to be some sort of contention regarding Aura Lila's justification for wanting to leave Juan. As Aura Lila herself explains later, “...it is sometimes better to put up with a man." In saying this, she was careful to qualify her statement by adding that a man should never hit a woman. The last sentence of this narrative section relates Aura Lila's insistence that although Juan wasted some of his money on other women and drinking, he always made sure to contribute to his family's well-being, thereby allowing them to continue living a comfortable lifestyle by the contemporary Nicaraguan standards. For Aura Lila to leave such a man would not have been seen as a justifiable option.

Aura Lila perceived herself as being caught between the social expectations surrounding women of her generation in Nicaragua and her own individual needs and desires. As she recounts her thoughts on women's roles and the character of men, she touches on some of the common gender-specific characterizations found throughout Latin America. These characterizations, typified in machismo for men and a corresponding role for women which emphasizes passivity and self-sacrifice. ${ }^{2}$ Despite the conflict she felt regarding the expectations placed on her, Aura Lila's narrative reflects her internalization of the accepted gender roles in Nicaragua.

In the narrative that follows, Aura Lila describes her relationship with Juan after their arrival in this country and currently in their later years. Although she characterizes their relationship as being more peaceful, she continues to stress her feeling that she has had to work doubly hard because she is a woman. According to Aura Lila her work now centers around taking care of her husband, despite her continued illness which resulted in a kidney transplant in 1991.

L: So, you're saying that after you came here you didn't have to put up with too much from him?

AL: No, because he began to behave when we came here. He changed, he was different. [L: Mhhmm. Why do you think that he changed?] Why? Because he wasn't able to see the same friends that he had in Managua. Those friends he used to go out with until all hours of the night and all that. He wasn't able to find that here. He found people like my 
sister Teresa's husband, for example, who didn't really go out too much. He didn't have anyone to go around with. He went to work and then straight home. You see? It was different. The kids were getting bigger and he began to change for the better. [L: So, you accepted a life with him then?] Oh yes. Of course, of course. Of course I accepted my life with him. In that respect, our life together became easier. But it got harder in another way.

Yes. I wasn't accustomed to the hustle and bustle of New York. That fast pace. I was accustomed to Nicaragua and my beauty salon, where I was always able to sit down and eat with my children. And in New York, I wasn't able to do that. I used to have to take my lunch to work with me to eat. I wouldn't even eat breakfast, maybe I had a chance to drink a cup of coffee. To catch the subway in the winter, during those snowfalls! No, no, no. That was all very hard for me to get used to. Nevertheless, I became accustomed to all of that. I became used to it. Yes. I began to run around to, mra, mra, mra. I would sing to myself as I ran to catch my train to take me to work. I used to get up at five in the morning to go and open the factory because I had so many kids to support. I used to try and go early so that I could earn a little more. I did it so that my children wouldn't want for anything. Yes, it was hard.

L: What about afterward? What was your life with him...?

AL: With him? I didn't really have any more problems. Thank God, right?

\section{L: And now?}

AL: And now he's quiet because he's an old man of 65 and I'm quiet, too! Because we can't do anything anymore. Yes. But, I'll tell you one thing. Up to a certain point, it pays to put with men. I'm not saying to let them treat you badly or hit you. But putting up with them counts for something. You get to be an old woman and.... Although I will tell you one thing. He is good to me, in my opinion. He goes with me here and he goes 
with me there. But I've been the kind of person that if I'm dying, I'll die alone. I won't say to you, "Linda Maria, I'm dying. Help me. Bring me my medicine." No. I am a loner in that respect. But not him.

If something happens to him - even though I might be sick and feeling like death-I get up and grab him, move him, rub him. I do whatever I can to help him. Coincidentally, he fell right there this morning. He fell and I ran to him. I'm not supposed to exert myself. But I picked him up and carried him. I don't expect him to do that with me.

He is different from me. I have been to carry the load, the one who has had to do everything. Even though I'm sick, I still feel like I'm the same person who can do everything she has always done. Yes. That's why I say, I've been through some very rough nights. I'll be awake and I can hear that he is choking. There are some nights when he chokes in his sleep, you see? So, I jump up and run to him, I grab him and move him around. I shake him, I move him until he comes to. I worry about him, don't think that I don't. My heart starts pumping when that happens and then, afterward, it's hard for me to go back to sleep. And then he'll say to me, "I'm sorry that I woke you." I tell him that it doesn't matter. I tell him to go ahead and wake me.

One night, I was in a deep sleep. I was so asleep that I wasn't even aware of where I was. But he was choking and so he starts to grab at me. Since I was sleeping, I tried to reach for him but couldn't find him. You should have seen! What an ugly feeling that was. I was reaching for him in my sleep, with my eyes closed and I finally got a hold of him. But I'm still sleeping, understand? And I call out, "What happened?! What happened?!" I jump up, finally, and grab him. And I ask him, "What was wrong with you?" So, he tells me. "Well, I had a cramp in my leg." [Both laugh.] Oh, Lord. So, I go over to him and tell him, "Come here." I rub his leg and straighten out his toes. I make him walk back and forth. I don't go back to bed until he's all right. And by then, I can't sleep.

And when he's choking, I stop and pray, "Lord, don't let anything happen to him." I ask the Lord for help, to fix whatever is wrong with him. But if something happens to 
me, I usually stay quiet. I don't say anything. I get up by myself. Right? I walk back and forth. I come out of the room and walk. I try to drink some water. I know that it's nothing, that everything will pass and I'll be fine.

In the section that follows, Aura Lila relates her apparent dislike for the gender socialization which was instilled in her. The conflict which Aura Lila appears to feel regarding the expectations for women of her generation is readily apparent. She describes the changes she feels have taken place in society, resulting in fewer restrictions placed on women. In addition, she briefly discusses the differences between the way in which she raised her daughter and the way in which she was raised. For Aura Lila, María received a different upbringing simply by virtue of having been raised in the United States. The section on Aura Lila's thoughts on her daughter is brief and was difficult to elicit for presentation in this text. As mentioned earlier, the relationship between Aura Lila and María has often been strained because of various choices María has made in her life. Following Aura Lila's narrative, we will examine María's thoughts on growing up in the United States and her perceptions of the gender expectations her mother, especially, held for her.

L: I wanted to ask you...?
AL: What hija?
L: You told me that you never wanted to marry, right? But, in Nicaragua... how do I say this in Spanish? Wasn't it expected of all women to marry?

AL: Yes. Yes. That is the shit they feed you.

L: Why?

$\mathrm{AL}$ : If you look at it, it is shit. 


\section{L: Why?}

AL: Because that is...you have to be married because if you're not then you are not looked upon nicely by society. Who is society? Do they feed you? Do they give you anything? Do they support you. But well, let's leave that aside. You have to get married because that is for your father, for your mother. Even if you don't want to get married, you have to.

L: And do you think that you raised your daughter in this manner?

AL: My daughter? Did I raise her that way? No.

L: Why?

AL: No, no. Because I raised my daughter and I was able to direct her actions up to a certain point. Then she went and did whatever she wanted. She was independent even when she was a little girl. She was. She used to do all of her own things for herself. I wanted to do things for her, but she never wanted me to. Ah? I wanted to feed her, she never let me. She did her own thing. So, I don't know. I tried to direct her up to a certain age. But after a while, I just couldn't. Yes.

L: And tell me, what do you think that... What does being a woman mean to you?

AL: What does it mean to be a woman? Well, I will talk to you about the woman from my times. A woman sacrifices herself, she is a mother, a wife, a housekeeper and she works. That, for me, is a woman.

L: And what was it like to be a woman in your time? 
AL: That's what it was like in my time. The woman was obligated to do everything, to serve the man. You had to do everything in the house. The man just worked. You had to do everything in the house, you had to raise your children and if you could, you had to work. Ah? Those were my times, mama. Everything is changing now, mama.

L: But do you think that these changes that we are seeing... are they good or are they bad?

AL: Good, because the man no longer has the woman stepped on like before. Because now if it doesn't go right with the man, the woman says, "Well, good-bye." And she leaves. Why? Because women today are better prepared to go to work. Not like before. They used to tell you, "No, no, no. You have to learn the business of the house because you are a housekeeper." That's what they used to put in your head. And there you were, stuck in the house doing everything for the man. The man was able to do whatever he wanted and you had to just stay there. Why? Because you couldn't go outside of your house to work. But not today. Today, women prepare themselves as much as men do. That's why. And that's why, for me, this is a much better era. Yes, mama.

L: And do you think that things in Nicaragua are just as different or do you think that women are more liberal here?

AL: No.

L: You think it's the same?

AL: Things have changed there, too. They've changed. 
L: Why?

AL: Well, because everything changes, mama. There is evolution. People aren't going to stay how they were. I went to Masatepe, and Masatepe is not the capital. You know that. It's a small town. Nevertheless, I saw that all of the girls were professionals. They had studied. The men, too. I was so surprised. All of the women are professionals. So in the capital, things must be better still. I'm talking to you about Masatepe because I haven't been to Managua in years. The people from Masatepe go to the capital to study.

Everything in this world is changing, don't think it isn't. Now the woman is much more clever. Now. She is more intelligent. She doesn't let the man push her around anymore. Yes, mamita.

L: But do you think that women are just different now or that their parents are raising them differently?

AL: No, no, no. It's that today, parents raise there children and at a certain age, the child decides what is right and what is not. You see? Before, that didn't happen.

L: Why? Why do you say that?

AL: Because of what I just said. Because things are advancing.

L: What do you mean things are advancing?

AL: Well, people are studying more. They have newer, better horizons, mama. That is how humanity is advancing today.

L: But how, specifically? I don't understand. Are you talking about technology? Or 
what? How does it advance?

AL: Well, because people study more and that's why things advance. Women are better prepared. They know what they want. It's not like before where you had to stay there, stuck.

L: Yeah. But do you think that women didn't know any better before or do you think that they weren't allowed to ...?

AL: Well, I'm going to tell you that they didn't allow you to do anything. They didn't. Before, there were no women lawyers. They didn't exist. No. You see? Women police officers, even less. Today, all of these exist.

L: I ask you because... You had mentioned that you weren't allowed to go to the door by yourself even. Right?

AL: Right.

L: Do you think that's how all women were raised in Nicaragua?

AL: Yes. Yes. That was the way we were raised by our parents. I think that maybe my parents were raised that way and so they raised us this way. And I am cut from the same cloth as my parents.

L: Did you raise your daughter the same way?

AL: I don't think so.

L: You don't think so? 
AL: I don't think so. No.

L: Why? So, you don't think you raised your daughter in that way?

AL: No. No, no, no. I did not raise her that way.

L: Did she have more liberties than you did?

AL: Oh yes.

L: In what sense?

AL: In what sense? Well, she was raised here. She was raised here. She saw different things, things that I probably didn't in my country. And so I think that she was raised differently. I wasn't raised that way.

L: In what way?

AL: The way she was raised here.

L: But how?

AL: With her being able to do whatever she thought was right. I wasn't raised that way. You see? I think that up to a certain point, it's good to give the child freedom. A lot of times, you learn from the child. Because since everything is advancing, right? Culture advances, civilization advances, studies advance, everything does. You end up staying behind. Yes. 
L: OK. Do you think that the way women are raised now is good?

AL: Yes, because now you prepare yourself. If you're with a man and you don't like the way he's treating you, you say, "Bye, have a nice life." You work. You can support your child. Isn't that the way it is now? Not before. Before, the woman used to have to stay there, stuck to the man because if the man left you, what were you going to do about the children? And that's that before you used to end up with a whole lot of kids. Women before were dumb. Just because you got stuck with one [referring to me directly], doesn't mean you had to have any more. You had to see that there was a stable foundation in your marriage. That's how it is, right? Not before.

You're not recording are you? [L: Yes. Aura Lila laughs. I stop the tape. She agrees to let me keep the previous passage in.]

L: You used to work in Nicaragua.

AL: Yes, because I had the beauty salon.

L: But did all women work?

AL: No.

L: Was it OK for you to work because you had a beauty salon?

$\mathrm{AL}$ : Was it $\mathrm{OK}$ ?

L: Yes. Why was it OK?

AL: Because I was in the house and I could keep an eye on my children. 
L: Because it was part of the house?

AL: Yes, of course. I had my beauty salon in the house. Even though they had nannies, I had to watch them, to make sure they ate. If not, I might have gone out of the house to work.

L: But in your day, not that many women worked outside of the home, right?

AL: No. No. No.

L: Why was it that way?

AL: Because.... Well, married women.

L: They didn't work?

AL: Single women did work. Yes. Single women. You see? But only in certain positions. There weren't any-as I told you-lawyers or doctors.

L: In what positions were women able to work?

AL: In offices. In offices, that was all right. They could type, take dictation, and they knew bookkeeping, things like that. They could work in offices. But they couldn't work in something very advanced, as a doctor or some other professional. Much less, as I told you, police officers. God forbid. It was looked upon badly.

In the old days when my mother was a young girl, her great-grandmother used to say that one day we would go around in the air. And my mother says that people used to ask her great-grandmother, "But how will people go around in the air? How terrible, don't say that!" And she insisted. Now we're flying through the air in airplanes. Planes didn't 
exist in those days, you see? You see then, all of the inventions and creations of man.

Time will pass and maybe you won't even see some of the things that are coming, greater inventions. But your daughter will see them. Sí, mama.

Aura Lila states that the changes in women's status have occurred as a consequence of the passage of time, due to the many changes in technology which she seems to feel forces people to change established patterns of thought. This explanation reflects her reluctance to fully consider or criticize the role her parents played in socializing her in the accepted ways of her generation. She does mention that her parents probably raised her in the same way in which they themselves were raised and acknowledges that she is "cut from the same cloth" as her parents. However when pressed, she is reluctant to further investigate the conflicts she encountered in the raising of her own daughter.

During the course of our interviews Aura Lila described some of these difficulties, particularly that María became pregnant out of wedlock at age 23. Aura Lila did not want me to publish extensive material regarding this situation which she characterized as a family crisis. As with other difficult issues, I managed to receive her permission to generally describe the situation. She described finding out about her daughter's pregnancy as one of the most difficult experiences in her life, one which made her feel "as though the world was crashing down around" her. All of her expectations for her daughter, she said, "the expectations for a wedding in a church to a good man," seemed to have vanished in the instant she heard the news. However, Aura Lila says that she felt she had no other choice but to support her daughter (she said she would never have advised her to seek an abortion) and claims to have intervened on María's behalf in making Juan accept the situation.

That María did not follow the prescribed course of marriage and motherhood indicates to Aura Lila that her daughter somehow acquired gender ideals different from her own. She argues that these ideals are rooted in the fact that María grew up in the United States where she learned to follow her own course of action and ignored the ways in which her parents attempted to bring her up. Here, Aura Lila reveals her strong belief-related to me often while growing up-that it is the duty of all children to follow their parents commands without question. It is at this point 
where Aura Lila's conflict regarding the dynamics of gender become evident. Because she has always expressed such a strong belief in the notion that parents are always correct, she can only criticize an abstract notion of society for imposing specific roles on women. In this way she not only absolves her parents of any blame for restricting her choices and opportunities in life, she also absolves herself for doing the same in her daughter's life.

I will now focus on Maria's narrative in an attempt to provide a more thorough understanding of the ways in which Aura Lila raised her daughter. Maria was not reluctant to speak about the birth of her only son Marco, now 17, although she did express some concern that her mother might be bothered by parts of her narrative. At 42 , she still lives with her parents and has done so for most of her life. Despite her age, María says that they still disagree with her viewpoint on various issues, particularly in the raising of her son. Like her mother, she characterizes the different perspectives she holds regarding gender on the circumstance of having been raised in the United States. However, she clearly identifies her parents in perpetuating established gender roles as the only suitable expectations within her life.

I began my interview with her by asking how she identifies ethnically.

L: I want to ask you about how you identify as a... as a ...you know. Well, let's say, how you identify as a national background. Would you consider yourself American?

M: Do I consider myself an American, more so than a Nicaraguan? Yeah.

L: Why?

M: Why? Because I know nothing about Nicaragua, really, basically. 'Cause I left, you know, when I was small.

L: How old were you when you came here? 
M: Seven years old.

L: And you haven't ever been back?

M: Uh, let's see. Twice. When I was eleven and when I was fifteen.

L: For how long did you go?

M: For the summer vacation. Three months. June, July and August.

L: Did you stay with you parents or with relatives?

M: I went with your mom.

L: Oh, really? Did you like it when you went?

M: [Pauses.] Yeah. It was all right. [Laughs. We both laugh.]

L: It was all right?

M: It was all right. It's just, it's just...I mean, I'm not real patriotic, you know? Like I see the Cubans and they say, "Oh, if Cuba becomes free, I'm gonna go." You know. “That's my homeland." I'm not like that, I don't know why.

L: What about... would you go back now? Do you think you would go back now?

M: I'm debating. [Laughs.] Es que, I don't have anything over there. I don't have anyone to go back... I would like to take my son, so he can see, but that's about it. 
L: OK. Do you think you would like it or...

M: [Pauses.] Mmmm. I don't know. [Laughs.] Would I like it? I don't know. I don't know. It'll probably just be interesting to go around and meet people, look at the places. 'Cause I really, whoever is over there, I don't know them...that well. And the place, itself, the country, itself, I probably don't remember much of it anyway, so... But, yeah, it would be OK, I guess. It's not something that I'm like, dying to go to, that I have to go to.

L: [Laughs.] OK. This is one of the questions that I want to ask you. Do you think that your mom raised you... Do you think that the way she raised you was different from other American kids...

M: Definitely.

L: ...your age?

M: Oh, definitely. 'Cause my mom raised me, you know, the old Latin way. Very, very, very strict. Very strict.

L: Like what?

M: Like what? [Laughs.]

L: Yeah, what do you mean by very, very strict?

M: Well, she wouldn't... they wouldn't let me go out even after I graduated. Well, first of all, I was placed in a boarding school, as you well know! [L laughs.] For four years with the nuns. So, those four years, were um, were like a total loss for me. You know? 
Because I didn't do anything that, that all the other young girls do, during your four years of high school. You know, I never went to the mall with my friends. Like even what my son is doing now. Going to the movies with your friends and hanging out with your friends, and the parties and the football games and the homecomings. I had none of that. I had none of that. And then, when I graduated from high school, they were even worse. They wouldn't let me go out, and I mean, I still went out when I was in my twenties already, and that's when all the problems came.

L: So, they wouldn't let you go out, even like... They wouldn't let you go out at all? You weren't allowed to go out?

M: They didn't want me to go out at all! [Emphasis hers.]

L: After you graduated from high school?

M: Uh-huh.

L: So, how did you manage to go out?

M: How did I manage to go out? Because I was, I mean... It wasn't like right after, it was, it was... [Sighs.] When I graduated from high school, I went into medical assisting school and then, from medical assisting school, then I started working. Once, I started working I was like twenty and they couldn't say no to me. They didn't want me to go out, but I still went out. They couldn't hold me down.

L: But did they want you to go out, like, with a chaperone or something?

M: No, that they never did. No. They just never liked, you know, whoever I went out with. 


\section{L: You mean, "going out" with guys?}

M: Going out with guys, yeah. See, the thing is that when you're in boarding school, you know... Like when you go to public school here or wherever, you know, everybody, all the kids are from that same neighborhood. So, you have friends there. Well, from boarding school, no. I mean, there were people, there were girls from Mexico, there were girls from Ecuador and you know, once you graduate everybody goes back to their countries. You know? So, it's not like I had friends. I had no friends. From high school. [Laughs.]

L: So then, you never had any girlfriends? You went out with Eva (her friend, originally from Nicaragua) didn't you?

M: Yeah. But Eva came, like, later on from Nicaragua. I was already... [makes blowing noise with lips] grown already. Yeah, I was already in my twenties.

L: And they just... And why do you think that they didn't like any of the guys that you went out with-that you liked?

M: Who knows, honey. [Both laugh.] Who knows. I don't know. I guess, no one was good enough for me. I guess, I don't know. I really don't know. Now if you ask her, it'll be something different, but... [Both laugh.] She'll say, "No, we were never like that." [Both still laughing.]

L: Do you think that because you were raised that way that you're raising your son differently? 
M: Definitely. [She gets closer to the recorder.] For sure. [Laughs.]

\section{L: In what way?}

M: In what way? I give him more freedom. Um, um. I trust him. I guess... I don't know if they didn't trust me. I guess it was just because I was a girl, you know, that they just overly-protected me. Or over-protected me.

L: They didn't treat your brothers like that?

M: Not at... Oh, no! Not at all. The guys could come at whatever time they wanted to come and it was great. “Oh, my son was out all night!” [Laughs.]

L: And they were actually like that? It was good?

M: Of course. Of course. But, you know, I guess young girls don't do that. You know? With Marco. Yeah, I'm totally different with Marco. I really am. I really am, and that comes...that becomes a problem, especially living here. 'Cause, of course, she doesn't agree with the way that I'm raising him but, that's how I'm raising him. I have to. I have to. I mean, I wish I could...You see, I think also, like I feel...I...It's not that I feel bad...Like, when he goes out, I say, "Oh my God, I hope nothing happens to him.” And I guess that's what every parent goes through, and maybe that's what they went through also. But I, I mean, you have to. I have to let him go. I have to let him experience. I mean, I'm not always going to have him next to my side. And I guess that's what they wanted with me. They were afraid that something was going to happen to me.

Maria clearly identifies the differences between the restrictions placed on her and the freedoms allowed her brothers with opposite gender expectations. She identifies these differences 
with the distinct cultures in which she and her mother were raised. According to María, her mother's beliefs regarding gender reflect the "old way" or Nicaraguan way of doing things. Although the differences between the way María was raised in contrast to her brothers appear to be clearly evident, she refers to her mother's denials that she was raised differently. It is interesting to note that María clearly refers to her mother when she says, "She'll say, "No, we were never like that." While María may have neglected to mention her father in this context because of the accepted notion within the family that Aura Lila was the primary disciplinarian, this omission may also reflect a deep-seated conflict with her mother over the way in which she was raised.

Throughout our interviews, María acknowledged her mother's strength, fierce independence and intelligence. Following the recorded interviews, she said to me, "You know if things had been different in my mom's life, she might have been able to study and become somebody. She was very intelligent. But she wasn't allowed to do that because she was a woman." I was left with the impression barely articulated within the narrative, that Maria recognizes the conflicts Aura Lila has experienced regarding gender. Yet, despite her mother's acknowledgment of what she characterized as the positive changes in women's status, there remains a sense that Aura Lila remains unable to fully accept her daughter's life choices.

Aura Lila and Juan have always expressed the desire that María live with them while she remains unmarried. They have often said that in this way, María will be able to save money on rent or a mortgage and enjoy the luxuries her salary as a hospital administrator affords her. However, these living arrangements can often lead to confrontations over the way in which she is raising her son or the men she chooses to date. María relates in the passage that follows the problems she encountered with her parents regarding dating in her twenties, including the circumstances surrounding her pregnancy. She states that she feels the way in which she was raised has contributed to the fact that she has never married.

L: What about the fact, do you think, that you still live with them? That they say that they don't want you to ever move out. Why do you think that they're like that? 
M: I don't know, honey. I really don't. [Both laugh.] I don't know.

L: Do you think that it's because they're still... uh, old fashioned in a sense.

M: I don't know. [Pauses.] Maybe. They've always treated me different than my brothers, even though she doesn't seem to think so, my mother. I don't know. She always wants me next to her, I guess. I don't know.

L: What about the situation... You've never been married.

M: Uh-huh.

L: Do you feel like you're never gonna be married?

M: Uh-huh.

L: You've just decided that you're not gonna...

M: It's not that I've decided. I think that's in my future.

L: Which is what? To be unmarried?

M: Unmarried forever. Yes, exactly. Be by myself.

L: Does that bother you or ...?

M: Ummm. Does it bother me that I'm not gonna be married? 
L: Yeah.

M: Ummm. It doesn't bother me, probably, as much as when I was younger. Yeah, because it would be harder now for me to get married. I think so.

L: Because you're used to being alone?

M: Yeah. I think it would be harder now, because I'm older. I'm set in my ways. Um, you know, before I marry, it's gonna have to be somebody that's able to support me. It's like I tell my friend Mario, it's gonna have to be somebody that either makes the same amount of money that I make or more. I said, because I'm not gonna take care of anybody. Um, so it's different. You know, you have different values, different needs. At this age, I mean you know, at 42 it's totally different than if I would have gotten married at 22. Definitely. So, does it bother me that I'm gonna be by myself? You know, I... I don't know. I don't know what the future holds. And I have a boy and boys usually get married and go.

And I think that's also what happens with us. I mean, my mom and my dad, they have two boys but they're married, they have their families and it's different. I don't have any responsibility except for Marco, so I guess I'm ...

L: They expect you...?

M: Yeah, I guess it's expected of me to be here and take care of them. I mean, when my mom got sick, I didn't work for a year, taking care of her. I had no income for a whole year, and I took care of her. I used to take her to the... well, you know. I took her to dialysis and the hospitals and everything. You know, and I guess, in the Latin culture, whatever, it's expected that always the daughter is there for her parents. Always. I don't know if that's how it is in American cultures, but you know, it's always in Latins that daughters are always there. I don't think it's that the sons don't want to. It's just that they 
have a totally different life now and other responsibilities. You know, the wife and the kids.

L: But do you think that if you were married that you would still have that same expectation of you?

M: I don't think so. No. I...Probably not. No.

L: No?

M: Probably not. No.

L: So, then what would they do?

M: They would, they would. I don't know. They would try to make do, I guess, without me. But I think that I'd be here more than, than...

L: ...than the boys?

$\mathrm{M}:$...than the boys. Yeah.

L: Do you think that they, in your opinion... Do you think that they're at all disappointed that you never got married?

M: No.

L: Why? 
M: I don't know, because I told you, I don't think that they, they, they... I don't think they feel that there's any man good enough for me. I don't know. They're very, son bien celosos. My parents are very jealous. Ask Jesus [a distant cousin from Nicaragua who is currently staying with the family], man. I mean, he'll be back here talking to me in the room and my father will come and see what he's doing. I mean, it's like, I don't know. They forget that I'm 42, that I can take good care of myself. I don't know.

L: And um, do you think...? 'Cause I had talked to your mom and she was saying that in Nicaragua, the people that you know, it's a small group of people that you have with which... from which to choose from. Like a husband or a wife. That everybody knows each other. Do you think that has something to do with it? That for them, you didn't marry somebody like... You know, that you didn't find somebody Nicaraguan and from a...

M: I did. Marco's father's Nicaraguan.

L: What about Marco's father? How do you think that, um, that they dealt with that? The fact that you're not married and that you had Marco.

M: Um, how did they deal with the situation? They never liked him, but they never liked anybody. They didn't like Rogelio, they didn't like Marco's father. They never liked anybody. So, I was never really able to bring anybody home.

L: So, then when they found out that you were pregnant..?

M: OK, well when they found out that I was pregnant, my dad was already living here. My mom was in New York and you know, she cried and whatever, but then, what could she do? I mean, I was 24 years old. It wasn't like I was 14 years old. I was 24 , I was 
working. So, you know.

L: So, she was living with you there when you found out that you were pregnant.

M: Yeah, but she moved down. She told my dad and according to her, I don't know, my dad was really upset and he didn't want to talk to me but that she talked to him. And he was OK with it.

L: Did you tell her right away or...? Did you feel like, “Oh God, I'm never gonna tell them?"

M: Yeah well, of course, I was afraid to tell her. But um, no, I told her. I got the courage to tell her and I told her and she wasn't happy with it, of course. She was crying and, and you know. I don't know if she even asked me who the father was, but I guess she figured out who it was.

L: She knew you were going out with him?

M: Uh-huh. Yeah, because even though they said no and, and he couldn't come to the house. Because he had told me, you know, "Talk to your mom, because I want to go and talk to your mom and your dad. So, I can go to the house $y$ hacer la visita ${ }^{3}$." You know how they do it, the Nicaraguan way. And she said, "No, I don't want him here."

L: Why didn't she like him?

M: Probably because he was black. Dark, I guess. I don't know.

L: Yeah?

M: Rogelio, too. They didn't like Rogelio and Rogelio was nice. He was nice. But he 
was 11 years older than me, so...

L: He was too old?

M: I guess. Too old and black.

L: [Laugh.] So, what about, um... So, you think that... the situation with you and your parents... Did that make it difficult to stay in a relationship with Marco's father?

M: I think that if my parents would have been different, as far as the way that they raised me and as far as the way that they were so jealous... They wouldn't let me go out or anything. I feel, my opinion-now, my mom says it's totally different. My mom says that I haven't been married because I haven't wanted to. It's been my choice. But I think if they would have been different as far as how they raised me, you know. If they would have let my friends come to the house, you know, guys, whatever, let me date. You know, do the normal American way, I think I would have been married by now. Definitely. Definitely, even though she doesn't believe so. She believes it's my choosing not to be married. [She laughs.]

L: Don't you think, though... From what I've read, you know, women in Latin America are raised to get married and have kids and have their own family? Don't you think it's kind of strange... Don't you think it's kind of strange that they never... I mean, do you agree with me that that's the expectation that they have of women?

M: Yeah. I don't know but they've been different with me. I don't know why. Maybe because she had it so tough in her marriage and maybe she didn't want me to go through the same thing. You know, when I was younger. But you know, now, deep down inside, now that I'm 42, I think she would love for me to be married. Now. 
L: Why?

M: I don't know, because she sees me that I'm older, now. My son's getting older. He's gonna, you know. He's gonna eventually... you know, find somebody and move out. You know? And then I'm gonna be alone. She's realizing that, now. That I'm gonna be alone. [She laughs lightly.]

L: And so she's worried about you because you're a woman.

M: Yeah. Exactly and then they're gonna be, you know, they're not gonna be here forever. And they'll be gone, so who's María gonna be.... So, I think more so than ever, she would like for me to be married. And I think now it's even harder... [She laughs again.] ...for me to be married.

L: But you're OK with—for now—not being married?

M: I'm OK with it.

L: Do you think that you'll ever live with somebody or...?

M: I would live with somebody. She would have a fit. [L laughs out loud. M laughs with her.] She would. She would have a fit.

L: Yeah.

M: But yeah, I would live with ... It's just hard, you know, because at my age... It's hard to find somebody because anybody, any man my age is probably already married or going through a divorce [L: Yeah.] and the young guys are... young. [Both laugh.] 
Maria concludes this passage by referring to the irony she finds in her mother's growing desire for her to marry as she enters her 40s. Although she says she does not feel as though she has disappointed her parents by never marrying, she does admit that she has in some way violated her parents standards. Again, we see conflict between the ideals espoused by María's parents and by the family's actual lived experience.

In living with her parents, María fulfilled another expectation which has often been expressed for Latin American women: that of the daughter who cares for her ailing and elderly parents (Gil and Vazquez 1996; Behar 1993; Esquivel 1993). In her oral history recorded by Behar (1993:160), Esperanza Hernández specifically identifies this expectation in this way:

There's nothing like a daughter. God gave me daughters, thank God. Between a daughter and a son, a daughter is thousands of times better than a son. Of course, if a son is good and his mother is ill, whether he's embarrassed or not, if there's no one else to look after her, then he has to look after her... But how often is a son going to look after his mother? A daughter, even if she's an angry sort, 'Orale, hija, even if you're angry, you've got to look after your mama.'

María admits that she would probably have returned home to care for her sick mother, even if she had been married and living outside of her parents' home. Despite her attempts at differentiating her views from those of her mother, she seems to have internalized and accepted the notion that daughters usually remain closer to their parents, while sons "move out and go.

The previous passage also clearly illustrates Maria's feelings that her parents thwarted her attempts at forging lasting relationships with men who might have eventually married her. She also feels that her parents often disapproved of her boyfriends on the grounds that they were black, referring to unspoken and underlying racial prejudices. Some other reasons, which were not explicitly referred to during these conversations but expressed elsewhere, include the fact that one boyfriend (Rogelio) was Dominican, which may have compounded their racial prejudice with what they perceived as an undesirable ethnic and class background-Dominicans and Puerto 
Ricans being considered by Aura Lila and Juan as being less industrious. Further, despite the fact that Marco's father was black, there was the added disadvantage that he was legally married at the time he was dating Maria—hardly a suitable choice for a serious boyfriend.

In the section that follows, Maria relates how her parents restricted her career choice.

She also returns to the topic of her pregnancy, to describe the way in which her older brother also attempted to regulate her behavior in accordance with their parents' beliefs.

L: How about "career-wise?" Do you think that they, that .... Since you were raised as strictly as you were, do you think that "career-wise" you were in any way... Were they just as strict?

M: Oh definitely. Definitely. Because when I graduated from high school, my dream was always to be a flight attendant. And when I graduated from high school, they said, "OK. So, you graduated from high school. What do you want to do?"

"I want to be a flight attendant."

"No, you can't be a flight attendant."

And then, I said, “OK, well I want to be a photographer, a professional photographer because I was photography editor of my yearbook in high school.

L: Really?

M: Yeah. Yeah. I used to love photography. And they said, "No, photography's for men. Da, da, da, da."

L: They said that it was for men?

M: Yeah, yeah. Es una carrera de hombre y que esto y que el otro. So, I knew what would make them happy was something in the medical field. And that's how it is that I 
got into the medical field. So, I said, "Well all right." So, I found, I don't know how I came about with medical assistant. And that's what I did. As long as it was something in the medical field, then they were happy.

L: Did they regard it as a woman's profession?

M: No, because you know in Latin... Latin people, it's like, “Oh. Un doctor, en medicina. O un abogado." You know, things like that. That's what they like. And always, it's medicine. Whatever you do in medicine, as long as it's in medicine. So, that's how I got into it. But I didn't go into nursing school until I came here to Florida. But my dream was always to be a flight attendant. I always wanted to be a flight attendant. Always. I even tried. I went to a few...

L: When you were younger, you tried?

M: No, older. Like in my 30 s, yeah. I tried. Oh yeah. I went to interviews with Pan Am, Eastern. Uh, United, American Airlines.

L: How did that make you feel when they told you that? You were just out of high school and you thought... Did you think that when you'd be finished with high school you would be able to... you were, like, an adult and you could....

M: No. No. Because you need to understand that I went into boarding school at 14 years of age. I was a kid, and for four years of my life, my life was, it was run by the nuns. It was dominated by the nuns, I guess. And you know, the nuns teach you, you know, you're a good kid. I was a good girl and you listen to what your parents said. You didn't rebel, you know? I mean, we went to mass every day. We said the rosary every day. We prayed every single day. And every day - I mean, Monday through Sunday- 
you know? You did chores, you said your prayers, you studied. That was my whole life for four years. So, of course, I come out and I graduate and I continue the same way. You don't go against what your parents say and you're good. The problems started when I met Rogelio and of course, they didn't like him. So, for them, that was me rebelling because I wanted to be with him. And then came Marco's father. You know, things like that. So, it was a problem. Like that. Yeah.

L: So, do you think that that was rebelling, getting pregnant and having Marco? Or...?

M: Oh, definitely. Marco wasn't a quote, unquote mistake. He was not.

L: Oh, you planned him?

M: Oh yeah. Oh yeah. Oh yeah. Yeah. He was planned. I figured out the day that I was ovulating and everything. I don't know if they know that, but... [She laughs. L laughs.] So, don't show the book to them. [Both laugh harder.] Oh yeah, Marco was planned. Marco was planned because they treated me like a kid. I wanted to be considered an adult, and I, I was 24 already.

L: Yeah.

M: Oh yeah. You know, I wanted a part of me that would love me and that's why I wanted a baby. Because during that time, I had no love from my parents. It was always fights. If my mother said black, I said white. You know? Like that. So. [L: OK.] So to them, yeah, it was rebelling. To them it was rebelling. I don't think it was rebelling. And see, I could never sit down and talk to them. And that's one thing that I have with Marco. I mean, we talk.

We talk. And I always tell him, let's sit down and talk. You know? We come to... we compromise. We compromise. 
Last night, he wanted to go out. I said, "OK. What time are you gonna be home?" I could never do that with my parents. Last night he says, "Ten-thirty."

“Ten-thirty?” I said, "No. Ten o'clock."

He said, "No. Ten-thirty."

I said, "OK. Ten-fifteen."

He said OK.

But I could never do that with my parents. You know, they always wanted me to go out with them. And it wasn't fun for me.

L: What do you mean "go out with them?"

M: Because they used to go out... [L interrupts: Now, go out with them?] No, when I was younger, that they were younger, too. They had their friends. Like you know, $L a$ Comadre and Gloria (family friends) and all those people. You know, they used to go out to their houses and to parties. But it was boring because, I mean, they all got drunk and had fun and I would just be sitting there because I had no one my age and nobody... I mean, I didn't drink. You know.

L: How about going out with your brothers? Did you ever go out with your brothers?

M: Oh no.

L: You couldn't go out with your brothers?

M: Well, no because my brothers weren't really into the same thing that I was into. Dancing and all that. No. No. And they were the same. Well, Ingemar was much, much younger. There's a seven year difference there. But with John, no because John— he would be one that would be good to interview. Um. John had the same beliefs as my parents did. Like that. With the girl, you gotta be strict and all that. I'm saying that 
because he was one that was very, very upset when I was pregnant. He didn't talk to me for the nine months that I was pregnant with Marco. And we lived in the same house. Because my parents moved out. During that time, in 1980, when I was pregnant, she was already making plans to move down. She moved down with Ingemar to be with my dad. I mean, to live here (in Miami) for good.

\section{L: Right.}

M: And I stayed up there because, you know, I had my insurance. My insurance was going to pay for everything and I was working. So, I stayed up there. So, the nine months that I was up there, um, John didn't talk to me. He was very, very upset that I was pregnant. Very upset. So.

L: And do you think that... How did you feel at that point? Did you... I mean, your family was leaving. The only brother you had there....

M: You know, I felt really bad and I think that's why.... I felt really bad and alone, and I think that's why... I think that's why God really was good to me and gave me such a good son. [She laughs a little self-consciously.] Because, um, you know, I had no one. I was extremely ecstatic because I was pregnant and I was gonna have a baby that I wanted. But at the same time, I was alone. I had no one to pamper me and you know, 'cause when you're pregnant you have your antojos ${ }^{4}$ and everything. And I had no one. The only one, the only one that I had was Eva (Maria's friend and the daughter of one of Aura Lila's friends, mentioned earlier).

And as much as my mother might hate her, uh, my mother can't stand her, but I will never, ever, ever, ever forget Eva. You know, because she was always there for me. On Fridays, she used to get paid and she'd say, " $C$ 'mon. I got paid. What do you feel like eating? C'mon, c'mon." You know and she was always... She was always there for me. And I, I can't forget that. I can't forget that. And, um, it was hard for me. It was tough 
for me. Even when I went into labor and John was in the house. I did not tell him I was in labor because, um, he didn't talk to me. So, why after nine months he hasn't talked to me, why should I tell him? You know, I'm in labor. So what I did was I stayed quiet; I called my friend, the neighbor, Claire. From across the street. And she took me.

L: And Teresa (our cousin, a gynecologist who lives in New York) was with you?

M: She was my coach. Yeah. She was the only one that I had because I had no one. If she wasn't there, I would have had my baby by myself. I had no one.

L: And at that point, were you still seeing Marco's dad?

M: Not seeing him, no. We talked. He knew I was pregnant and all that, but we weren't seeing each other. No. But he came to see [the baby] at the hospital.

María's experience of having very few people to support her during her pregnancy has shaped her current definition of womanhood, which requires a great deal of strength and selfreliance. She contrasts this with what she characterizes as her mother's beliefs. In María's estimation, her mother still holds these beliefs quite strongly despite her statements to the contrary during our interview. However, she claims to understand some of her parents' motivations for the choices they made in raising her. María has often referred to her disdain for having been forced to remain in a boarding school during her high school years. Indeed, she has often said that she cried every week for a year during her parents' weekly visits, and that when her father appeared to relent and seemed ready to allow her to return home, her mother refused. However, she recognizes that her mother was trying to provide her with an opportunity that only upper class Nicaraguan women would have received.

In concluding our interview, I asked her to articulate her thoughts on womanhood and women's roles. 
L: Do you ever feel...like if you could change things, do you think you would want to come here to the United States, again if you had the choice?

M: Oh yeah. Oh yeah. No, I mean, it was a great opportunity. I just, I don't know. I just wish maybe I would have been stronger and just leave. You know.

L: Leave what? You mean, the house?

M: The house, yeah. Sooner.

L: Mhmmm.

M: I still plan to. [To the recorder.] Don't put that in. Erase that. [Both laugh.]

L: Do you think that, so you think that for you, Nicaragua, you know... Did you ever wonder what it was like? What it would have been like to grow up there?

M: No, not really. But I know I wouldn't have had the same opportunities.

L: To do what?

M: ...that I've had here? To find work. Everything. Everything. Education-wise. You know. I think my parents.... You know, when I tell people that I went to boarding school, they say, "Wow, what did you do? What kind of girl were you?" Because that's what people think.

L: Yeah. 
M: But you know, at least the Nicaraguan way, if you go to boarding school it's because.... You know, rich people send their kids to boarding schools. That's how it is in Nicaragua. Here, it's like all the bad kids are the ones that were sent away to boarding school.

L: Right.

M: And I think, you know, my parents were just trying to give me.... They thought that it was, you know.... I guess I saw it differently than they did and I still do because to them, it was, they were giving me a good education. Um, but to me, I saw it as I missed out on all that.

L: What is your idea of, you know, what a woman should be? Do you think that it's different from your mom's definition of a woman?

M: Oh definitely.

L: What do you think your mom's definition of a woman is?

M: I think my mom's definition of a woman is to, um.... I mean, just look at what she's doing now. You know? She's sick. She can barely walk but, I mean, she's there cooking for my father, washing for my father, ironing his shirts for work. Um, I think that's my mom's idea of a woman. To always take care of your man, regardless of whether, you know, your sick or not. And that's not my idea of a woman. [She laughs.]

L: What's your idea of a woman? 
M: To me-I guess because you know, I've had to raise Marco on my own and everything. I guess my idea of a woman is someone who's strong. Who can make it on their own without any man's help. You know, not to have to depend on anybody or you know, the government to help you out. I mean, sometimes you need the help, but listen if you can make it on your own and go to school and become a professional, then that's my idea of a woman.

And who knows? And maybe that's why I haven't been able to find the right man. Because, um, I can not be just completely.... And like your mother, too. You know? Just do everything for this man. No, I mean, what's wrong with his hands? [L laughs.] He can do some things, too. He can wash. You know? He can iron, he can cook.

L: Would you consider yourself a feminist?

M: I don't know. I never have, but I don't know the meaning of "feminist." I never have. You know, maybe I am but I never considered myself one. I don't know. I don't know. Do you think I'm a feminist?

L: I guess so, based on that....

M: I guess. But I've never considered myself a feminist. I mean, you know, I still like for the man to be polite and everything. That's what I've taught Marco.

L: Do you think...? What do you think that being a feminist means?

M: Um, well, I think that plus, I don't know. Maybe a feminist doesn't like to be treated, like, politely by men. Like, you know, opening the door for them and things like that. I like that in a man. I like that. I don't know if feminists like that. You know? 
L: Yeah. I think so. The ones that like men. [Both laugh.]

M: Well, all right then yeah. So, I guess I am a feminist then. That likes men. That's not too bad.

In concluding her narrative, María seems intent on differentiating her definition of womanhood from that of her mother's. To a degree, these women's definitions do differ. However if we consider that Aura Lila presents herself as a strong, independent woman, who at times in her life made do with little help from her husband, the image which emerges touches upon María's definition of womanhood. Of course, the independent woman which Aura Lila uses to represent herself remains at odds with many of her daughter's views. She still does not approve of divorce, raising children out of wedlock, or couples who live together outside of marriage, particularly if her daughter happens to be participating in such behavior. The ideals with which she was brought up limit her ability to accept such changes in domestic roles, despite her marvel at in-vitro fertilization, which she says will one day free all women from the domination of men. The primary contradiction regarding gender revolves, for Aura Lila, around the fact that she can criticize the expectations foisted upon her throughout her life, while remaining unable to move past criticism and accept the changes occurring around her.

These gender role changes which have caused so much conflict for Aura Lila and by extension, María, are inextricably linked to class and ethnicity. Efforts to shield Maria by placing her in a boarding school and the harsh screening of her boyfriends illustrate examples of the family's attempts at raising a proper, Nicaraguan woman, educated to uphold the ideals of the upper classes. Such efforts seem in keeping with the family's aspirations for upward mobility, as well as an attempt to counter the effects of any downward mobility they may have experienced in moving to the United States. By closely examining both of these women's narratives, we can begin to see the ways in which gender, class and ethnicity intersect within individual lives. In addition, we can see the complexity surrounding attempts at preserving cultural traditions, meanings and codes (Yanigasako, 1996). 
'Literally, leavening agent used in baking. Inocencio was relating to his daughter his belief that men have a fundamental flaw in their make-up.

${ }^{2}$ This role has been identified in the academic literature as marianismo. The name refers to the virtues of the Virgin Mary, who is thought to be the ultimate role model for "proper women" (Gil and Vazquez 1996). While machismo has received widespread acceptance and is used throughout Latin America, marianismo is less popular in usage although it has been used in the academic literature (Fernández-Kelly 1991).

${ }^{3}$ Maria's boyfriend wanted to make an official visit to gain her parents' permission to date their daughter exclusively. Maria cites this episode as an example of her her parents' extreme position regarding dating.

${ }^{4}$ Cravings. 


\section{A. Research Motivations/Methodology}

My work with Aura Lila Callejas began in March 1993 as part of an undergraduate project in my Qualitative Research Methods course. I was interested in examining the immigration experiences of three Nicaraguan women, all related to me and living in Miami. I intended to examine the experiences of these three women who immigrated within three distinct historical periods of migration in terms of the roles they played within their families and communities.' The women I chose for this project differed in age and socioeconomic background. By comparing their daily experiences from the time of migration, I also hoped to be able to come to some understanding of the perspective which these women used to identify themselves as "Nicaraguan," a category which distinguished them somehow from other Hispanics, as well as from native-born American women. In addition, I wanted to examine the transition each of these women made, to some degree, from identifying as simply Nicaraguan to identifying somewhat with being an American-even if that transition was simply an ambivalent affirmation of the lifestyle they experienced living in the United States.

As mentioned, the women I chose to interview for this project were all related to me. Because of my inexperience, I thought that working with women whom I had known closely or with whom I could cultivate a relationship through another family member, would be fairly easy. However once I began interviewing the first two informants, I realized that there were many issues that I had not considered. The first problem I encountered was that I had not given much thought to my involvement within the project, both as a narrator/observer and as a somewhat significant active participant within each of these women's lives. I was also naively assuming that I would conduct an interview, during which these women would provide me with neat and tidy answers. I unconsciously held on to this position, even though my undergraduate education led me to question the notion that history is created through the accumulation of neat and tidy "facts." Looking back, it is impossible for me not to laugh at my naiveté given the ambitious goals I had outlined for my undergraduate project.

The other significant problem which I encountered became apparent once I began work- 
ing more intensively with a single informant, my great-aunt, Aura Lila. I decided to focus solely on her because the stories of Nicaraguans who arrived in the United States prior to the Nicaraguan Revolution are largely absent from the academic literature. I once again naively assumed that since I had a great deal of data on Aura Lila, the closeness of my relationship would enable me to continue to gather additional data. However the more I worked with Aura Lila, the more I had to examine my own relationship with her and the role she played within my family. In addition, working with her caused me to question my own feelings regarding my family's history and how I situate myself within that history.

The data used in this project were collected during various interviews conducted from 1993 to 1997. My initial session with Aura Lila Callejas lasted 90 minutes and took place in early March 1993 in her home in Miami, Florida. This initial interview consisted of a basic question and answer session which followed a predetermined questionnaire. The initial interview questions addressed personal information, such as date and place of birth, number of siblings, number of children and occupation. The questions then progressed to attempt to gauge Aura Lila's feelings about particular experiences. (For instance: "How did you feel about leaving Nicaragua?")

As I stated earlier, I felt that my initial interview would elicit neat and tidy answers to my questions. I suppose I thought that I would be able to fill the spaces underneath my questions on my answer sheet and that the information would suffice for the project. While the information that I elicited from Aura Lila did suffice for the purposes of my undergraduate project, I found that I was left with many more questions than answers. It was this feeling of "unfinished business" that helped persuade me to continue working with Aura Lila as a primary subject. Moreover, following my first interview with her, I sensed a subtle change in our relationship; I felt that I had become the official repository of all the family stories which she carried with her. I could not tell if she was merely glad to have someone to listen to her tell and retell her stories of our past or if she felt that I might be the one to document these stories and pass them on to later generations. As I continue this project, it has become almost vitally important to me to secure as many of these stories as I can, in hopes that some day I can pass them on to later generations.

My second session with Aura Lila lasted over a week-long period in June 1995, during 
which we traveled to Masatepe, Nicaragua - her town of birth. The visit had been her first to Nicaragua in 15 years. We were joined by her two surviving sisters, Esperanza and Castalia, and one of the nieces she raised. This visit allowed me to be in constant contact with Aura Lila and to closely observe her behavior while in her home country. The trip was special for me because it was only my second trip to Nicaragua as an adult. Prior to 1995, my last visit there occurred only a few months before the Revolution when I was eight years old. In Masatepe, I was able to do some archival work to try to reconstruct my maternal family's genealogy, which seems to fade two generations prior to Aura Lila's birth. My cousin and I spent a day at the Masatepe Records Office trying to find as much information about our ancestors as we could and then returned to interview Aura Lila, Esperanza and Castalia about their recollections. I stayed up late with Aura Lila on three nights, talking about her childhood memories, as well as her adult impressions of Masatepe and Nicaragua, in general. She allowed me to tape these conversations, and I generally tried to stay away from a structured question and answer format. Instead, I allowed her to lead the conversations and only asked questions if I wanted her to elaborate further on a specific topic.

Following our return from Nicaragua, I conducted four more informal recorded sessions with Aura Lila. I have also interviewed other members of our family in order to enhance the information which she has provided me. Much of these interviews are featured at the end of the thesis, where I discuss the generational differences within Aura Lila's family. I have also decided to discuss Aura Lila's citizenship process at the end of this work because of her decision to undergo the process so late in life.

In addition to my desire to examine the immigration process through an individual's life history, this project provided me with the opportunity to conduct research on my own family history. By researching my family, I hoped to gain some insight into the historical experience of Nicaraguans in the United States. Growing up during the 1970s and 80s, the daughter of parents born in Nicaragua, it always seemed to me that our numbers as an ethnic group were not as significant as those of other Hispanic groups, especially Mexicans, Puerto Ricans, and Cubans. Prior to the Nicaraguan Revolution of 1979, I was often asked if I belonged to one of these three groups when meeting someone for the first time. Although my family has always had a large number of Nicaraguan acquaintances- in New York, during my early childhood, and in Miami, 
where we now reside - it always seemed to me that Nicaraguans were a small minority within the larger Hispanic population in the United States.

The academic literature would appear to confirm this impression. Although the United States has maintained a long-standing relationship with Nicaragua since the mid-1800s, most of the academic literature concerning U.S.-Nicaragua relations concerns the Revolutionary period (1978-1991) and after. This is especially true in the case of Nicaraguan women. Much of this literature examines the changes to the status of women as a result of the Sandinista Revolution (Likogle 1996; Centro de Educación y Comunicación Popular 1992; Brenes Pena 1991; de Montis et al 1990; Vargas Escobar 1990; Collinson 1990; Pérez Aleman et al. 1989; Palma 1988; Maier 1985). While such literature is important in providing an examination of the lives and public roles of some Nicaraguan women, it is neither inclusive, nor does it easily generalize to represent "the Nicaraguan woman." In addition, the academic literature seemed to reinforce my early impression that Nicaraguans were considered an insignificant ethnic/minority population prior to the Nicaraguan Revolution by the larger U.S. society, as well as by other Hispanics. However, as I encountered growing numbers of friends, acquaintances and contacts made by my family in New York, California and Florida, I was led to question these assumptions. Did Nicaraguans, as a group, constitute a distinct community within the United States prior to the Revolution?

\section{B. My relationship with Aura Lila}

When Aura Lila arrived in the United States in 1963, she brought her 17 year-old niece, Teresa, along with her own three children. This young woman who decided to leave her home country with her aunt was my mother. My mother had already been given the opportunity to travel to the United States. A year earlier, my grandmother Juana, asked my mother if she wanted to come to the United States with her, her second husband and the rest of her brothers and sisters. My mother contemplated her mother's offer and decide to remain in Nicaragua at the time. She now says that she chose to remain with Aura Lila's family because "in reality, I was used to living with her." She also cites her mother's economic instability as being an important factor in her decision. Without having to care for my mother, Juana and her husband would still be respon- 
sible for four children in a new country. According to my mother, she felt that she would be adding a burden to her family by coming along.

I explain here the circumstances of my mother's arrival in this country in order to clearly show the ties by which I am bound to Aura Lila-ties which were bound decades before I was born. Aura Lila, my great aunt, raised my mother for most of her life. She has always served the role of grandmother in my life. According to family lore, my biological grandmother, JuanaAura Lila's older sister-was the apparent victim of "bad luck" when it came to choosing husbands. As a result, she suffered through two marriages to alcoholic husbands, who very rarely provided economically for the family. During her first marriage, when Juana did not have enough money to support her three children, she sent them to live at her parents' house. Aura Lila, then living with her parents, was primarily responsible for watching the children and became a primary maternal influence in their lives. This role was enhanced when Aura Lila's mother-the children's grandmother-died. Following her mother's death, Aura Lila found herself caring for her aging father, her younger brothers and her sister's children.

Of Juana's children, my mother is said to have been most attached to her grandparents' home and Aura Lila's care. There is a story, which I have heard from various family members and which serves as mythical justification for my mother's attachment to her grandparents' home and to Aura Lila. When my mother went to live in her grandparents' home, as a toddler, she slept with her grandmother in the same bed. They shared that bed until the night that her grandmother died in her sleep. Following her grandmother's death, my mother returned to live with her parents and her siblings. Soon after her return, she became deathly ill with a fever which seemed to have no cure. Juana called Aura Lila to come quickly and to bring a doctor.

When Aura Lila rushed over to my mother's bedside with a physician, she found her hallucinating. My mother sat up, suddenly, and told Aura Lila that she had seen and talked to her grandmother and that her grandmother was coming to take her away. Hearing this, Aura Lila began to cry and turned to the doctor for advice. The doctor told her to take the child away from her mother's house and return her to her grandparents' home or else she would surely die. Aura Lila hurriedly wrapped my mother in blankets, took the child back with her and placed her in her grandmother's bed. Within a day, it is said, my mother recovered from her fever and regained her 
health.

Having heard this story throughout my life, I have come to recognize that it serves the purpose of justifying the replacement of Juana with Aura Lila within my mother's life. My grandmother died unexpectedly in a car accident when my mother was 20 years old. Because of the circumstances of Juana's rather short life, she was not a constant presence in her children's life. Although my mother always recognized Juana as her mother and has perhaps, idealized her in memory, she was, in fact, raised by Aura Lila. This fact has often been a point of contention within my mother's family. There has always been an implicit questioning of my mother's preference for Aura Lila's care, as if she somehow failed in maintaining loyalty to her mother. This tension surrounding my mother's relationship with Aura Lila has rarely been verbalized. Nonetheless, I have always been aware of it.

Aura Lila is also related to me, through marriage, on my father's side of the family. At age 22, she married Juan José Callejas, my father's elder brother. My father, the youngest of 14 children, spent most of his adolescent years in Juan and Aura Lila's household after his mother's death, when he was 14. As a result, my mother and father effectively grew up together in the Callejas household. Although they did not date until they were older and living in the United States, it was in Aura Lila's house (and under her watchful eye) that they began what has thus far been a nearly lifelong relationship.

Aura Lila, then, has always been an important figure in my own personal history. A strong-willed and at times, stubborn woman, she has always loomed in my mind as the matriarch who has held our family together. This image of her has only been enhanced by the fact that she helped to raise so many of her nieces and nephews. Aside from helping to raise Juana's children, Aura Lila also helped to raise her sister's three children, following that sister's death from breast cancer. As mentioned previously, she also provided a home for my father during his teenage years. Aura Lila managed to welcome all of these children into her home, despite having three children of her own.

I spent most of my early childhood in the house in Queens, New York owned by Juan and Aura Lila. When my mother and father first married, they could not afford to live on their own. They lived in an additional room, which was added on to the elder Callejas' house. This was my 
first home when I was born. Even after my parents and I moved out to an apartment of our own, we spent most of our weekends and special events at the Callejas house. Consequently, many of my earliest memories are centered on the house in Queens filled with people.

As I continued work on this project, I made a startling discovery. Aside from using Aura Lila as a convenient and interesting subject for study, I found that the more I learned about her, the more I learned about myself. Because of this project, I have had to confront a number of issues regarding my own notions of gender roles, ethnicity, and my own position within the myriad and complex familial relationships that make up the social group that $I$ have always known as "my family." These issues have been extremely difficult to address because I have tried to observe my family while remaining an intimate insider. Consequently, I have found that Aura Lila Callejas is not the only subject of this work. I feel that I am also a subject of this study, even though I was often not physically present during many of the events described by Aura Lila. In a sense, this project has allowed me to reconstruct my own personal history in a conscious manner. This reconstruction has often taken place without my knowing what sorts of "truths" or answers I will have to confront nor how I will feel about them. Because of this situation, I have had to fight a certain degree of ambivalence with regards to completing this project. I have also had to take special care, throughout, to edit my work carefully. I have not done so with the intention of discerning some sort of objective fact or truth from Aura Lila's narrative, but rather to make sure that I do not recognizably alter her story with my own recollections and interpretations of the past. I have had to take special care not to let the subjective nature of my relationship with Aura Lila overshadow the story she tells.

When I first became interested in examining Aura Lila's life, I was mainly concerned with trying to elucidate her sense of her own identity. I wanted to know if she still thought of herself as Nicaraguan, despite having spent over half of her life in the United States. Aura Lila has only returned to Nicaragua three times in her thirty-plus years of living in this country. Moreover, she did not seem too interested in identifying herself with the growing Nicaraguan community in Miami. Many times during my informal conversations with her, she expressed an ambivalence about her link to Nicaragua. On the one hand, growing up in Nicaragua had shaped her way of looking at the world. On the other, she had been gone for so long, at times it seemed 
that the only apparent connections to her homeland were the food she still cooks for her family and the Spanish which she speaks at home.

I was also curious to uncover any connection she felt to this country. Aura Lila mentioned continuously throughout our recorded conversations that she had come to this country on her father's advice, in order to provide her children with a better standard of living. She has often told me that although her life in this country had been one of hard work, she felt that her children's lives were substantially better than what they would have been had she and her husband remained in Nicaragua. However, Aura Lila also found many aspects of life in the United States contrary to what she expected. The most obvious of these, recorded on numerous occasions during our interviews, was her belief that the educational system in the United States was inferior to the one she had known in Nicaragua. Aura Lila's assertion mirrors those of many immigrant parents from Central America (Súarez-Orozco 1989). This belief extends itself in her opinion -expressed to me throughout my life-that in the United States, children were not raised to respect their elders in the same way that they were in Nicaragua.

Once I began to examine Aura Lila's opinions and beliefs about her relationships with these two countries that had shaped her life, I found that I could not examine her identity without pausing to look at my own. If I was trying to fit Aura Lila along a continuum with Nicaragua on one end and the United States on the other and having trouble placing her, where was I to place myself? As the second-generation child of immigrant parents, my connection to Nicaragua had always been a tenuous one. As of this writing, I have only been there four times in my life, and I was an infant during my first visit. Growing up, Nicaragua seemed as far away to me as it did to my schoolmates and everyone else who asked me where my family was from and were not quite sure of where Nicaragua actually was when I answered. My connection to the United States has been no less confusing. While I now identify myself with larger movements and populations within this country, including Latinas and other women of color, I could barely make these connections while I was growing up.

Further, my connections with Nicaragua and the United States are often in direct contradiction to those made by Aura Lila. She identifies me as an American and has periodically questioned what I might feel for a country I barely know. Also, she could never accept my 
admiration for the Sandinista Revolution, which was brought about by a broad-based coalition committed to ending what I consider to be the tyrannical and unjust rule of the Somoza dynasty. She has never accepted my condemnation of the Somozas nor would she listen to my protests that the family had achieved a tenuous peace in their country through brutal, ruthless and tyrannical means. For me, being able to enter into the dialogue on Nicaragua's political history serves to help me reclaim my own sense of a Nicaraguan identity. For Aura Lila, my comments might verge on the traitorous but then again from her perspective, I barely know what I am talking about in regards to Nicaragua and its social history. 


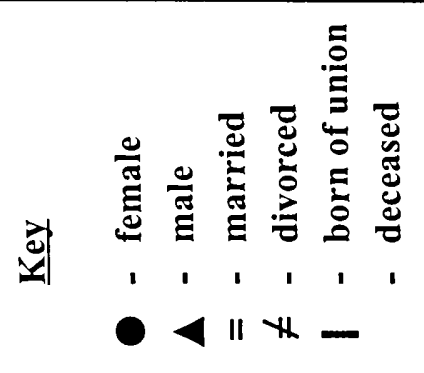
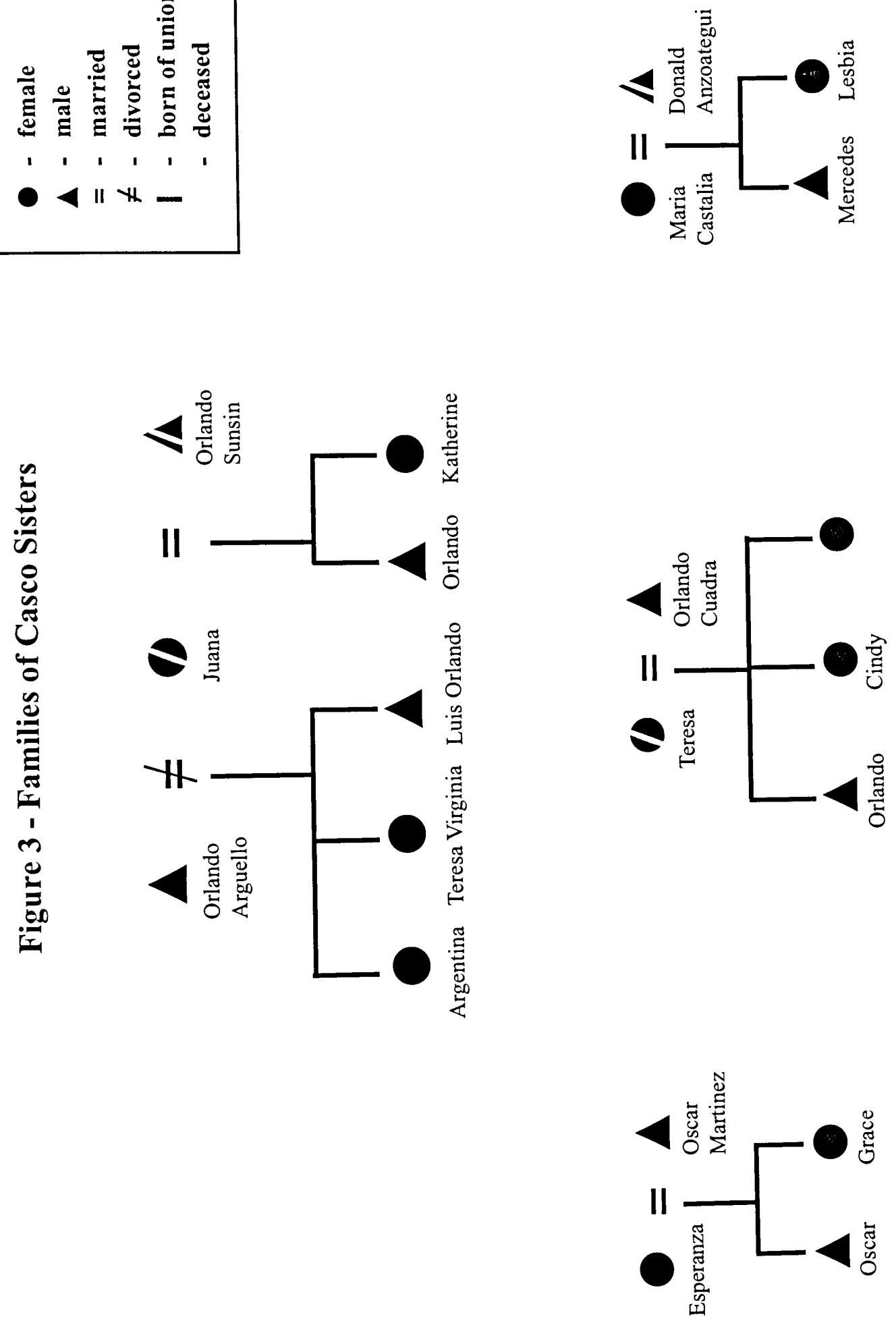

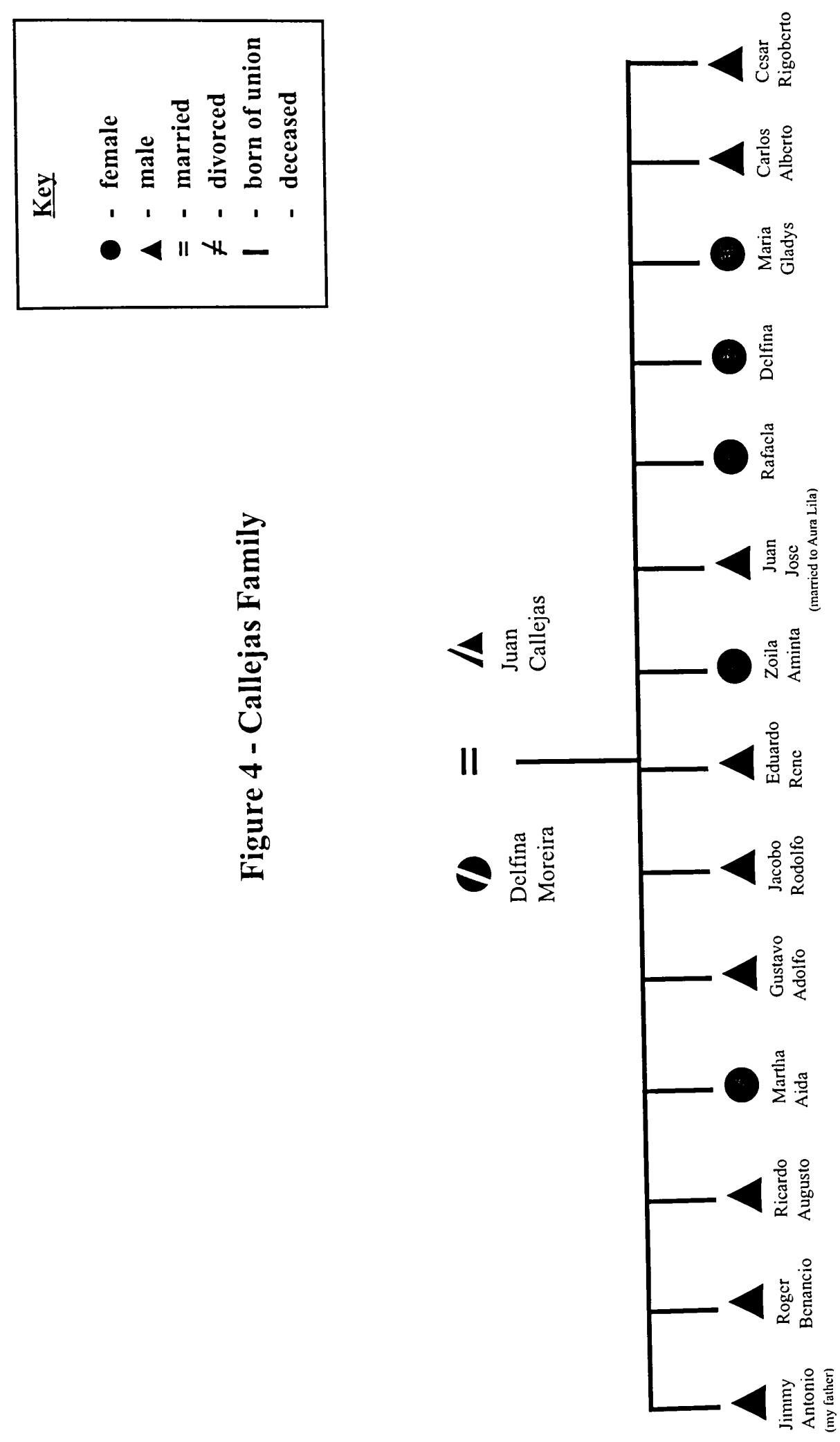


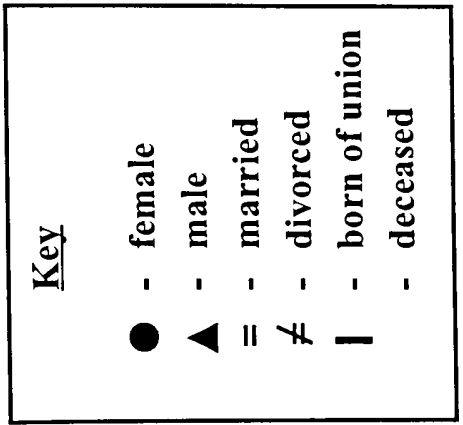

$\underbrace{\infty}_{0}$
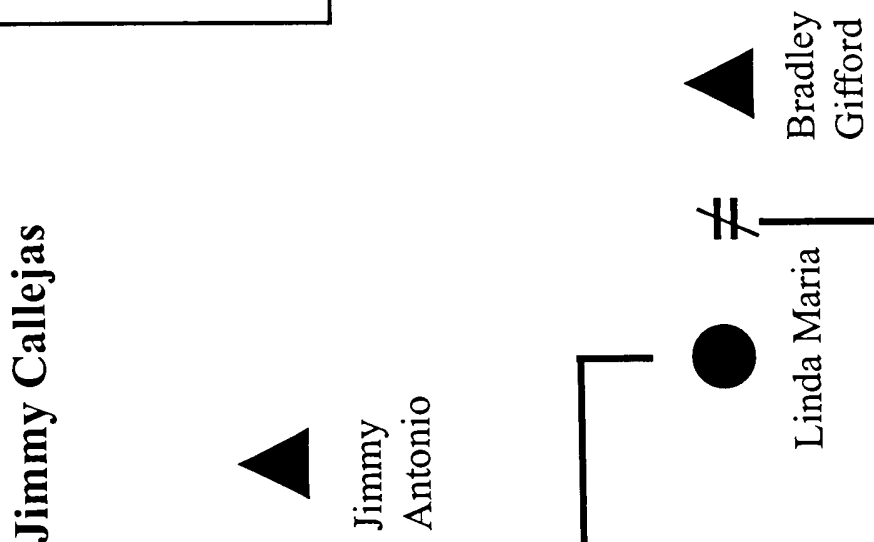

H

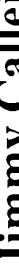

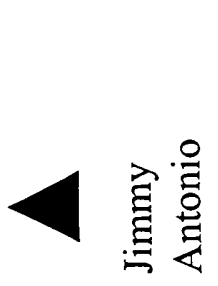

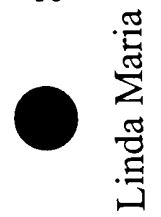

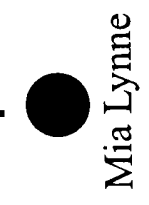

을

5

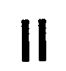

:

壱

is

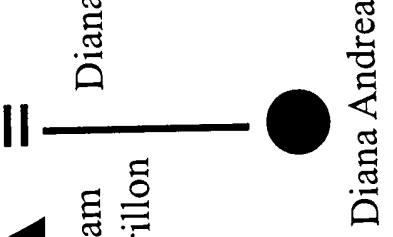

릴

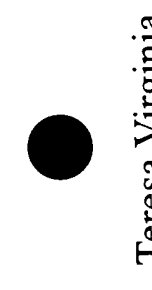

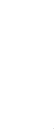

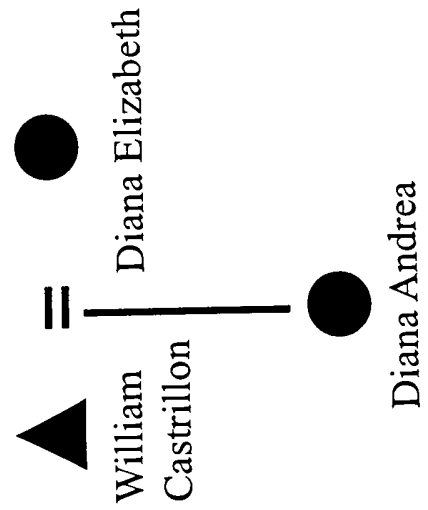




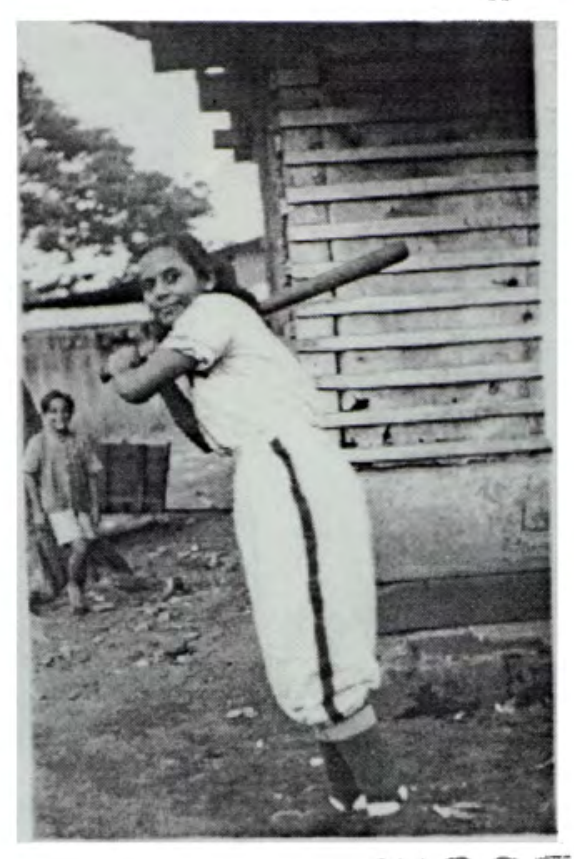

Figure 6 -Aura Lila at age 15.

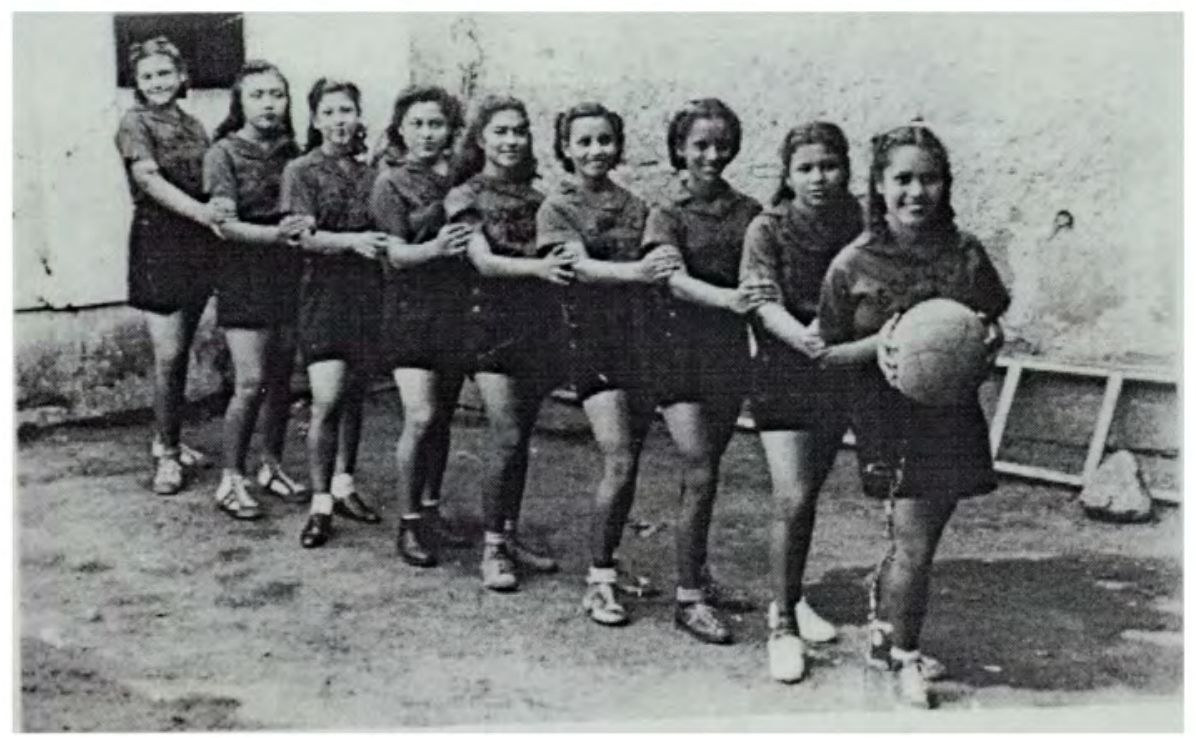

Figure 7 -The high school volleyball team which includes my grandmother, Juana, age 15. She is fourth in line from the front. 


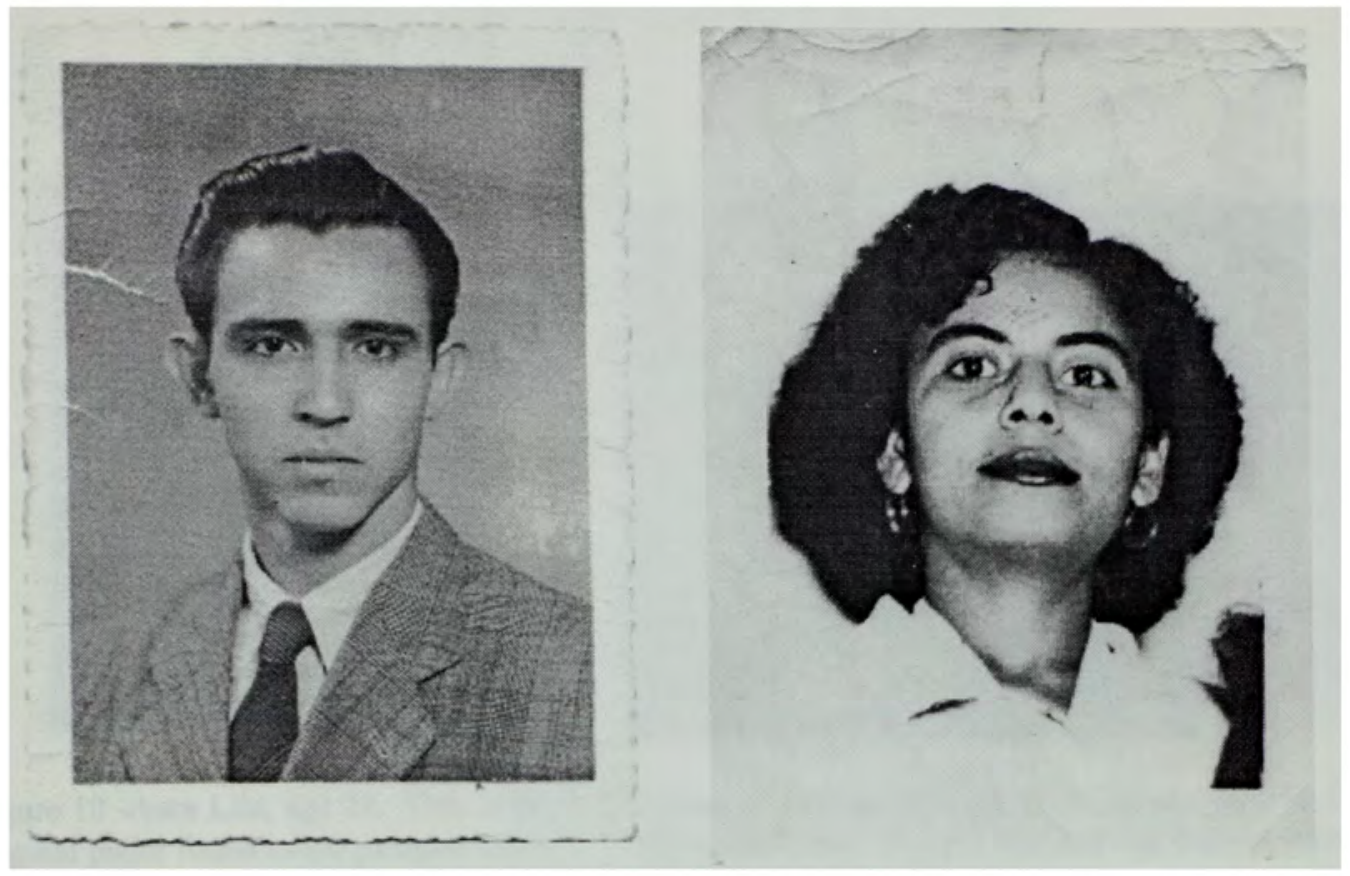

Figure 8 - Juan and Aura Lila in 1951, both aged 21. These are the original photos they first exchanged expressing their love for each other.

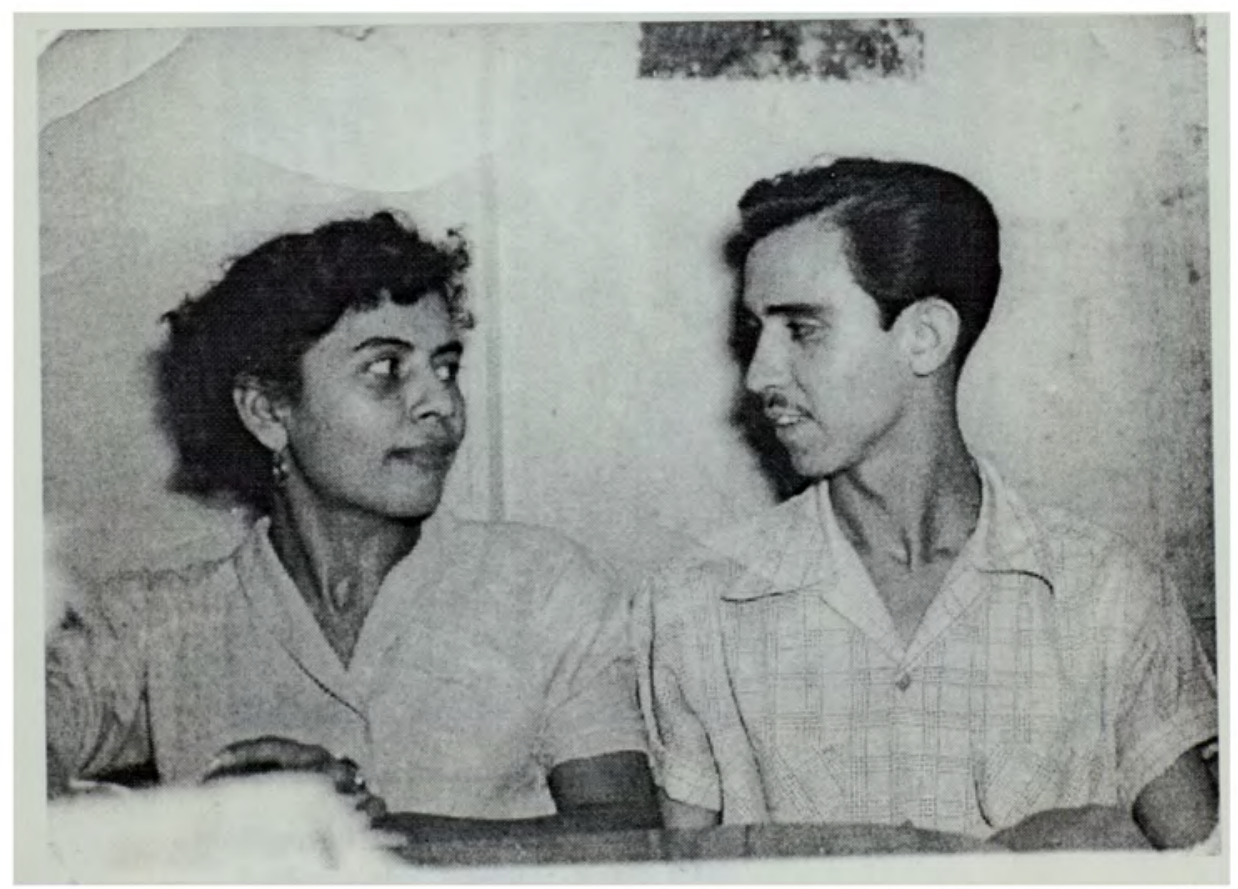

Figure 9 - Juan and Aura Lila at a party. The date is uncertain although it was probably taken between 1950 and 1952 prior to their wedding. 


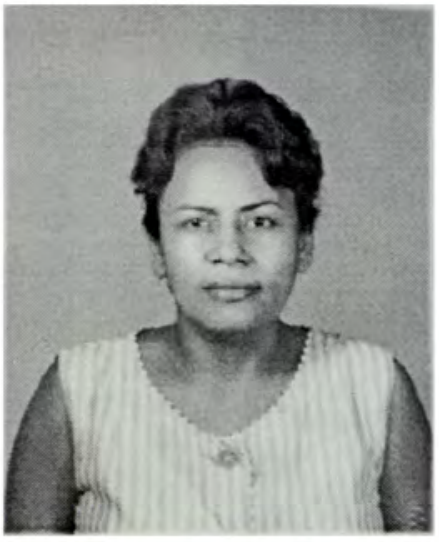

Figure 10 -Aura Lila, age 29. This is the original photo found in her passport when she left Nicaragua for the United States.

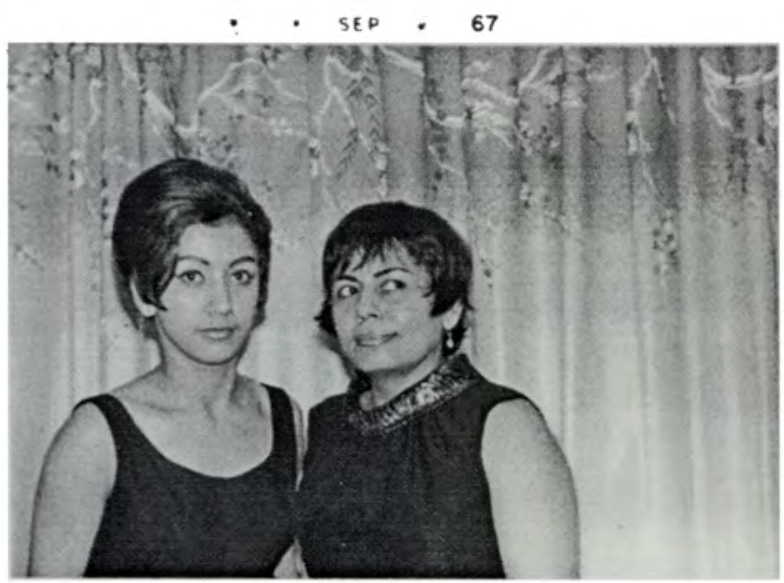

Figure 11 - My mother and Aura Lila at a party in 1967. My mother was 22 years old and had not yet married. Aura Lila was 37.

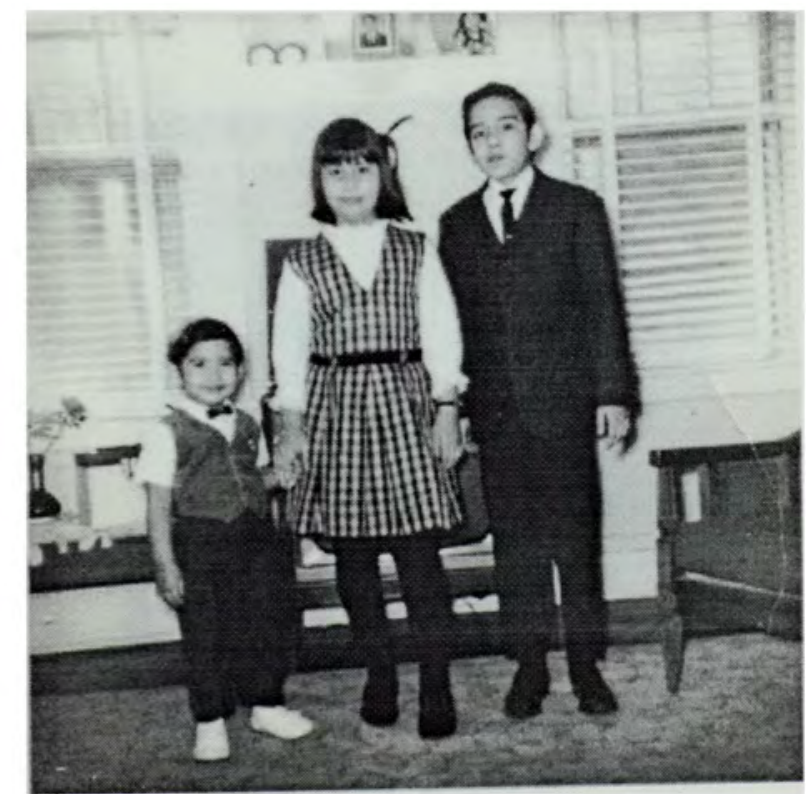

Figure 12 - Aura Lila's children in Queens, 1965.

Left to right: Ingemar, Maria, John. 


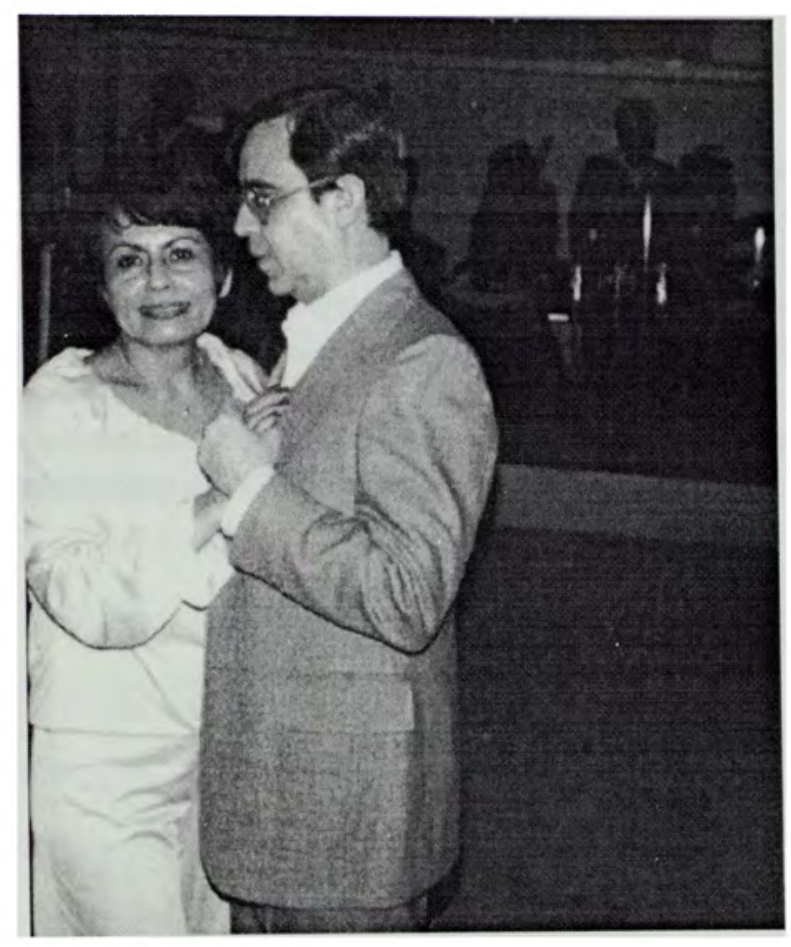

Figure 13 - Aura Lila and Juan at their 25th anniversary celebration in a Queens ballroom, 1977.

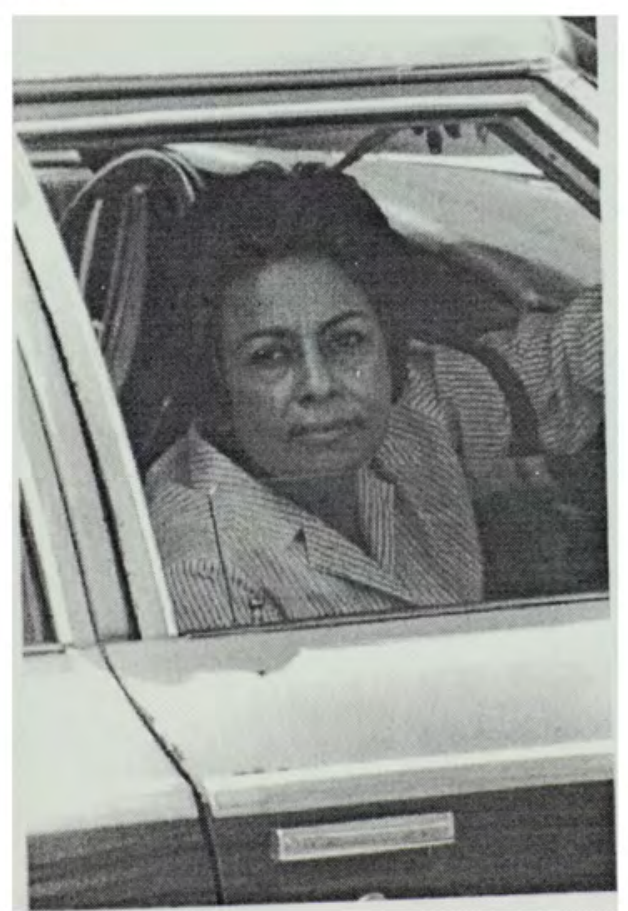

Figure 14 - Aura Lila on her way to work at the factory in 1980 . 
'The dates I chose to assign to these periods are listed as follows:

The pre-revolutionary era, which I identified as occuring between World War II and 1972. I chose these dates to identify the period during which Aura Lila's migration took place because by 1942 Anastasio Somoza Garcia was well-established as president, while 1972 marks the occurrence of the devastating earthquake which destroyed most of Managua. The earthquake of 1972 is considered by many Nicaraguans to be a significant socio-historical marker signaling the coming change at the end of the decade.

I identified the second and third historical periods as the revolutionary era (1978 through $1991)$ and the post-revolutionary era (1992 to present), respectively. 
This project was undertaken with the intent to examine one woman's migration experience in an attempt to identify various theoretical issues. The first of these concerns the motivations for international migration and how well individual motivations "fit" with the existing body of migration literature. Oral history has proven useful in presenting some of the ways in which structural factors combine with personal motivations to provide the impetus for Aura Lila's journey of international migration.

Specifically, Aura Lila's narrative revealed her conception regarding her family's social class background in Nicaragua. The Callejas family, as noted in Chapter 2, was able to afford numerous luxuries unattainable for the majority of Nicaraguans in the late 1940s to the early 1960s. The family's affluence was tempered however, by factors such as family background and education attainment levels. For the purposes of this study I identified Aura Lila and her family as belonging to a middle-class strata because of their aspirations for greater material wealth combined with their lack of sufficient social capital to identify themselves as members of Nicaragua's elite. I consider these aspirations to have been shaped to a large degree by the significant influence of U.S. popular culture in Nicaragua, which was reinforced by Anastasio Somoza Garcia's ascension to power in 1937. The Somoza family's love and support of U.S. culture and policies has been well-documented (Randall 1994; Walker 1991; Lethander 1968).

I believe my work with Aura Lila has served to highlight some of the existing gaps in the current literature regarding Nicaraguans in the United States. It is my contention that the historical relationship between Nicaragua and the United States can be identified as an example of the relationships forged within the international division of labor identified by Wallerstein (1974). The United States with its exportation of cultural images of material wealth served to stimulate the material aspirations of the Callejas family — aspirations which were becoming increasingly difficult to achieve. This scenario is in keeping with works which examine motivations fueling migration and identify the majority of migrants as those individuals or groups who possess sufficient material and social captital to undertake the often difficult process of international migration (Massey et al. 1993; Portes and Rumbaut 1990). The continued exportation of U.S. 
cultural values to Third World or periphery nations combined with falling wages in the periphery can only continue to fuel the desires of people who wish to migrate to the United States and other industrialized nations.

Aura Lila's narrative also served to highlight the importance of the family within the overall process of her migration from Nicaragua to the United States. In keeping with the literature on network systems, Aura Lila's family exhibited a history of internal and external migration which helped shape Aura Lila's beliefs regarding migration. Throughout her narrative Aura Lila identifies migration as a means to increased opportunities for her family and she identifies this belief as originating with her father. Such instances provide evidence of Boyd's assertion regarding the transmission of cultural norms and values within the family which heavily influence decisions to migrate (1990). Moreoever, family connections were intrinsic to the process by which Aura Lila and her family arrived and settled in the United States. The Callejas family was able to use its connection to Aura Lila's sister already settled in New York City as a menas to enter the country legally. Aura Lila's sister, Teresa also helped the Callejas family in a variety of ways, including providing the newly arrived family with a place to stay and securing employment for Aura Lila. The importance of such aid through migration networks has been documented in a number of works (Massey et al. 1987; Piore 1979; Bohning 1972).

While much of Aura Lila's story remains unique and specific to her family's history, her narrative can be related to the growing body of literature focusing on women's life histories. A number of feminist researchers have identified oral history as a successful means of identifying the importance of gender in women's lives (Swindells 1992; Personal Narratives Group 1991; Gluck and Patai 1989). Throughout Chapter 3, Aura Lila describes the ways in which her conception of appropriate gender roles shaped her life. Aura Lila's acceptance of responsibility for an extended family in her early twenties provides strong evidence of her internalization of the social expectations surrounding women in Nicaragua at the time. Despite an often articulated aversion to marriage, Aura Lila says she agreed to marry as a consequence of her decision to assume the caregiver role for a large group of people. By her account, Aura Lila assumed this responsibility without ever being asked. She did state that as the only single woman left in her father's household however, she could not have turned away from the needs of younger siblings, 
very young nieces and nephews and her ailing father. In this circumstance, the importance of gender in shaping Aura Lila's decision to assume specific responsibilities and to marry becomes clearly evident.

In comparing Aura Lila's story to oral histories of immigrant women, similarities emerge regarding the changes to specific beliefs regarding gender roles. For instance, Aura Lila identifies a number of ways in which the general position of women has changed in relation to the men in their lives. Although Aura Lila does not identify these changes specifically with different expectations existing in the United States, I am inclined to believe that they exist as simply more than a worldwide improvement of women's status. Like Michiko Tanaka in Through Harsh Winters (1989), Aura Lila identifies her beliefs with a social environment molded in a different time and a different place with limited opportunities. In both cases however, the changes in opportunity and fundamental change in beliefs regarding acceptable gender roles are readily evident in the lives of these women's daughters. For Tanaka, the divorces of several daughters served as a source of concern and wonder. In Aura Lila's case, Maria's decision to become a single mother has served as a source for continued family conflict.

The inclusion of Maria's narrative provided added perspective to Aura Lila's reflections on gender. Although Aura Lila claims to admire the changes which allow women to pursue an infinite number of opportunities and possibilities, she has had difficulty accepting such changes within the context of her own family. Comparison of Aura Lila's story to other oral histories shows similarites, as for instance to Crespo's (1994) work on Puerto Rican immigrant women which highlights the intersection of race/ethnicity, class and gender in the reshaping of gender codes within a foreign cultural context. Crespo identifies the ways in which first generation women send their second-generation daughters contradictory messages regarding appropriate behavior. On the one hand, Crespo's sample exhorted their daughters to study in order to remain independent of male economic support, with the qualification that their independence eventually end in marriage. As with the women in Crespo's sample, Aura Lila's relationship with Maria illustrates the complexity involved in attempts at maintaining specific cultural values within changing social contexts, as illustrated in the experiences of other immigrant groups (Yanigasako 1991). 
Throughout my examination of Aura Lila's narrative, I have often wondered if the manner in which Aura Lila presents herself-the individual struggling to succeed despite numerous obstacles-is somehow related to the internalization of U.S. cultural values. According to Strauss (1997), this plot schema which relates a protagonist who faces obstacles and ultimately triumphs, is a very typical North American plot. This myth of the triumphant individual, identified by Reich (1987), is said to pervade in American interviewees' life stories because most Americans are exposed to such narratives from early childhood (1997: 6). However, for someone like Aura Lila who did not grow up in the United States and in fact, came here with many of her cultural perspectives shaped at age 30 , the use of this plot schema is rather interesting. It is impossible to say given the space constraints of this work whether Aura Lila's narrative reflects simply the internalization of U.S. values. Many cultures could probably lay claim to the use of such a narrative device in the creation of texts. Yet, I suspect that such a case can be argued given the extent of U.S. influence in Nicaragua during her youth and her family's support of such influence.

In contrast, Randall (1991: 13) might argue that the prevalence of this particular plot schema within Aura Lila's narrative may reflect a long Nicaraugan history of female self-reliance and strength, dating back to the strong tribal and matrilineal characteristics of the indigenous family model. Quoting Murguialday, Randall emphasizes the creation in Nicaragua of a family model, in which the stable presence of a man is the exception rather than the norm. She traces the development of this model to the development of the agro-export industry which necessitated the absence of males, leaving women to oversee care of the family and home. Such a cultural history may also give rise to the use of the individualistic plot within Aura Lila's narrative. It may also explain her self-reliance in her mode of representing herself.

This self-reliance and individualism, however, is tempered by Aura Lila's insistence on following the ways of her parents particularly in aspects relating to gender roles. "Have you already served your husband dinner?" This was the inevitable question that came without fail whenever my husband and I visited Aura Lila. It never helped to protest or argue that my husband, a grown man, had long known how to serve himself. She never even said, "That's not the way things are done." The men are served first. Period. That's the way it's always been done in 
her house. Whenever I tried to deflect this situation by joking that I preferred to be served by my husband, Aura Lila would laugh but admonished me about not behaving as a wife should. She usually continued to ask me the same question thereby pressuring me to conform to the rigid gender roles with which she grew up. I often felt I was left with only two options: acquiesce to her authority and serve my husband so that her questions will cease, or simply walk away and attempt to ignore her. Neither of these methods left me feeling satisfied.

I recount this personal anecdote in an effort to explain that although I was able to discuss issues of gender on broad terms with Aura Lila, I could not escape the cultural environment which she maintains in her home-an environment which shaped many of the women in my family, including her daughter María, my mother and myself. In examining Aura Lila's beliefs about gender roles, I have had to examine my own and at times struggle to come to an understanding about the conflicts which I face in many areas of my life. This has been particularly difficult considering my present domestic situation involving divorce and single parenthood. While Aura Lila's views often seem antiquated to me, her influence in my life has been so great that I can not help but measure my own life against hers. Although we often differ in our sentiments regarding many issues, it is my hope that she lives to see this work and to know that it has been written with the highest respect and regard for her. 


\section{List of References}

Abu-Lughod, Lila. 1991. "Writing Against Culture." In Recapturing Anthropology: Working in the Present. Richard G. Fox, ed. Santa Fe: School of American Research Press.

Alcalay, Rina. 1995. "Hispanic Women in the United States: Family and Work Relations." In Latino Employment, Labor Organizations and Immigration. Antoinette Sedillo López, ed. Vol.4 Latinos in the U.S. Series. New York: Garland Publishers.

Baca Zinn, Maxine. 1994. "Adaptation and Continuity in Mexican-origin Families." In Minority Families in the United States: A Multicultural Approach. Ronald L. Taylor, ed. Englewood Cliffs, NJ: Prentice Hall.

Behar, Ruth. 1996. The Vulnerable Observer: Anthropology That Breaks Your Heart. Boston: Beacon Press.

1993. Translated Woman: Crossing the Border with Esperanza 's Story. Boston: Beacon Press.

Behar, Ruth and Deborah A. Gordon, eds. 1995. Women Writing Culture. Berkeley, Los Angeles, and London: University of California Press.

Brenes Pena, Ada Julia. 1991. La Mujer Nicaragüense en Los Anos 80. Managua: Ediciones Nicarao.

Browning, Harley L. and Nestor Rodríguez. 1985. "The Migration of Mexican Indocumentados as a Settlement Process: Implications for Work." In Hispanics in the U.S. Economy. George J. Borjas and Marta Tienda, eds. Orlando, FL: Academic Press.

Bulmer-Thomas, Victor. 1987. The Political Economy of Central America Since 1920. Cambridge: Cambridge University Press.

Bustamante, Jorge and Geronimo Martínez. 1979. "Undocumented Immigration from Mexico: Beyond Borders but Within Systems." Journal of International Affairs. 33: 265-284.

Boyd, Monica. 1989. "Family and Personal Networks in International Migration: Recent Developments and New Agendas." International Migration Review. 23: 638-671.

Castro Silva, J.M. 1947. Barómetros Economicos de Nicaragua. Managua: Banco Nacional de Nicaragua.

Centro de Educación y Comunicación Popular. 1992. Cultura y subordinación de la mujer en Nicaragua. Managua: CANTERA.

Chávez, Leo R. 1988. "Settlers and Sojourners: The Case of Mexicans in the United States." Human Organization. 47: 95-108. 
Collinson, Helen, ed. 1990. Women and Revolution in Nicaragua. London and NJ: Zed Books.

Esquivel, Laura. 1993. Como Agua Para Chocolate. New York: Doubleday.

Fawcett, James T., Siew-Ean Khoo and Peter C. Smith. 1984. Women in the Cities of Asia: Migration and Urban Adaptation. Boulder: Westview Press.

Fernández-Kelly, María Patricia. 1994. "Political Economy and Gender in Latin America: the Emerging Dilemmas." Working paper. Washington, D.C.: Woodrow Wilson International Center for Scholars.

Fox, Richard G., ed. 1991. Recapturing Anthropology: Working in the Present. Santa Fe: School of American Research Press.

Gabaccia, Donna. 1994. From The Other Side: Women, Gender and Immigrant Life in the U.S., 1820-1990. Bloomington: Indiana University Press.

,ed. 1992. Seeking Common Ground: Multidisciplinary Studiesof Immigrant Women in the United States. Westport, CT: Greenwood Press.

Gil, Rosa María and Carmen Inoa Vázquez. 1996. The Maria Paradox: How Latinas Can Merge Old World Traditions with New World Self-Esteem. New York: G.P. Putnam's Sons.

Gluck, Sherna Berger and Daphne Patai, eds. 1991. Women's Words: The Feminist Practice of Oral History. New York and London: Routledge.

Grasmuck, Sherri and Patricia R. Pessar. 1991. Between Two Islands: Dominican International Migration. Berkeley, Los Angeles and Oxford: University of California Press.

Kikumura, Akemi. 1981. Through Harsh Winters: The Life of a Japanese Immigrant Woman. Novato, CA: Chandler \& Sharp Publishers, Inc.

Krause, Corinne Azen. 1991. Grandmothers, Mothers, and Daughters: Oral Histories of Three Generations of Ethnic American Women. Boston: Twayne Publishers.

Leeds, Anthony. 1976. "Women in the Migratory Process: A Reductionist Outlook." Anthropological Quarterly. 49:69-76.

Lethander, Robert. 1968. “The Economy of Nicaragua." Ph.D. Dissertation. Duke University.

Límon, José. 1991. "Representation, Ethnicity and the Precursory Ethnography: Notes of a Native Anthropology.” In Recapturing Anthropology: Working in the Present. Richard G. Fox, ed. Santa Fe: School of American Research Press.

Likogle, Stephanie. 1996. Gender, Faith and Practice in Nicaragua: Constructing the Popular and Making 'Common Sense.'Brookfield, VT: Greenwood Press.

Logan, Kathleen. 1997 "Personal Testimony: Latin American Women Telling Their Lives." Latin American Research Review. 
Maier, Elizabeth. 1985. Las Sandinistas. México, D.F.: Ediciones de Cultura Popular.

Massey, Douglas S., Rafael Alarcon, Jorge Durand and Humberto Gonzalez. 1987. Return to Atzlán: The Social Process of International Migration from Western Mexico. Berkeley: University of California Press.

Morokvasic, Mirjana. 1983. "Women in Migration: Beyond the Reductionist Outlook." In One Way Ticket: Migration and Female Labor. Annie Phizacklea, ed. London: Routledge and Kegan Paul.

Newman, Katherine S. 1988. Falling from Grace: The Experience of Downward Mobility in the American Middle Class. New York: The Free Press.

Olivera de Vazquez, Mercedes, Malena de Montis and Mark A. Meassick. 1990. Mujeres: Panoramica de Su Participacion en Nicaragua. Managua: Cenzontle.

Osborne, Bennie Lee (Dot). 1996. "A Generational Analysis of Survival Strategies of Southern Rural Black Women.” M.A. Thesis. Florida International University.

Palma, Milagros. 1988. Nicaragua: Once Mil Virgenes. Bogotá: Tercer Mundo Editores.

Pérez, Lisandro. 1994. "Cuban Families in the United States." In Minority Families in the United States: A Multicultural Approach. Ronald L. Taylor, ed. Englewood Cliffs, NJ: Prentice Hall.

Pérez Aleman, Paola, Diana Martínez and Christa Widmar, eds. 1989. Industria, Genero y Mujer en Nicaragua. Managua: Instituto Nicaragüense de la Mujer.

Personal Narratives Group. 1989. Interpreting Women's Lives: Feminist Theory and Personal Narratives. Bloomington and Indianapolis: Indiana University Press.

Piore, Michael. 1979. Birds of Passage. Cambridge: Cambridge University Press.

Pomata, Gianna. 1996. "Blood Ties and Semen Ties: Consanguinity and Agnation in Roman Law." In Gender, Kinship and Power: A Comparative and Interdisciplinary History. Mary Jo Maynes, Ann Waltner, Birgitte Soland and Ulrike Strasser, eds. New York and London: Routledge.

Portes, Alejandro and Robert L. Bach. 1985 Latin Journey: Cuban and Mexican Immigrants in the United States. Berkeley: University of California Press.

Portes, Alejandro and Ruben G. Rumbaut. 1990. Immigrant America: A Portrait. Berkeley: University of California Press.

Powdermaker, Hortense. 1966. Stranger and Friend: The Way of Anthropology. New York: W.W. Norton. 
Ramos-Escandon, Carmen. 1996. "The Social Construction of Wife and Mother: Women in Porfirian Mexico, 1880-1917. In Gender, Kinship and Power: A Comparative and Interdisciplinary History. Mary Jo Maynes, Ann Waltner, Birgitte Soland and Ulrike Strasser, eds. New York and London: Routledge.

Randall, Margaret. 1994. Sandino's Daughters Revisited. New Brunswick: Rutgers University Press.

Reich, Robert B. 1987. Tales of a New America: The Anxious Liberal's Guide to the Future. New York: Vintage Books.

Rosaldo, Renato 1989. Culture and Truth:Renewing the Anthropologist's Search for Meaning. Boston: Beacon Press.

Shopes, Linda. 1996. "Using Oral History for a Family History Project." In Oral History: An Interdisciplinary Anthology. $2^{\text {nd }} E d$. David K. Dunway and Willa K. Baum, eds. Walnut Creek, London and New Delhi: Altamira Press.

Simon, Rita James and Caroline B. Brettell, eds. 1986. International Migration: The Female Experience. Totowa, NJ: Rowman and Allanheed.

Strauss, Claudia. 1997. "Plot Versus Partly Integrating Schemas: When Narrative Does Not Tell the Whole Story." Paper presented at the American Anthropological Association Meetings. Washington, D.C.

Suarez-Orozco, Marcelo. 1989. Central American Refugees and U.S. High Schools: A Psychosocial Study of Motivation and Achievement. Stanford: Stanford University Press.

Swindell, Julia. 1992. In Seeking Common Ground: Multidisciplinary Studies of Immigrant Women in the U.S. Donna Gabaccia, ed. Westport, CT: Greenwood Press.

Tedlock, Barbara. 1991. "From Participant Observation to the Observation of Participation: The Emergence of Narrative Ethnography." Journal of Anthropological Research. 47: 69-94.

Vargas Escobar, Milu. 1990. Mujer y Constitución. Managua: Centro de Derechos Constitucionales.

Walker, Thomas W. 1991. Nicaragua: The Land of Sandino. $3^{\text {rd }}$ Ed. Boulder, San Francisco and Oxford: Westview Press.

Williams, Anne. 1993. "Diversity and Agreement in Feminist Ethnography." Sociology. 27:575-590.

Yanigasako, Sylvia Junko. 1985. Transforming the Past: Tradition and Kinship Among Japanese Americans. Stanford: Stanford University Press. 